\title{
Optimal Operating Mode for \\ Enantioseparation of SB-553261 Racemate Based on Simulated Moving Bed Technology
}

\author{
Faldy Wongso, K. Hidajat, Ajay K. Ray \\ Department of Chemical and Biomolecular Engineering, National University of \\ Singapore, 10 Kent Ridge Crescent, Singapore 119260; telephone: + 656874 \\ 8049; fax: + 656779 1936; e-mail: cheakr@nus.edu.sg
}

Received 19 June 2003; accepted 11 May 2004

Published online 16 August 2004 in Wiley InterScience (www.interscience.wiley.com). D0I: 10.1002/bit.20182

\begin{abstract}
The performance of the simulated moving bed (SMB) technology and its modification, the Varicol process, was optimized using an experimentally verified model for the enantioseparation of SB-553261 racemate. Single and multiobjective optimizations have been carried out for both existing as well as design stage and their efficiencies were compared. The optimization problem involves a relatively large number of decision variables, both continuous variables such as flow rates, switching time and length of the columns, as well as discrete variables like number and distribution of columns. A state-of-the-art new optimization technique based on a genetic algorithm (nondominated sorting genetic algorithm with jumping genes) was utilized which allows handling of these complex optimization problems. The optimization results showed that significant improvement could be made to the chiral drug separation process using both the SMB and the Varicol process. It was found that the performance of a Varicol process is superior to that of a SMB process in terms of treating more feed using less desorbent or increasing productivity while at the same time achieving better product quality. Optimum results were explained using equilibrium theory by locating them in the pure separation region. (C) 2004 Wiley Periodicals, Inc.
\end{abstract}

Keywords: simulated moving bed; Varicol process; multiobjective optimization; Pareto set; genetic algorithm; chiral separation

\section{INTRODUCTION}

Simulated Moving Bed (SMB) technology is an intriguing innovation that has been exclusively applied to the purification of different types of products ranging from petrochemical (Broughton and Gerhold, 1961), food (Azevedo and Rodrigues, 2001), consumer goods (Charton and Nicoud, 1995), protein (Jensen et al., 2000), and fine chemicals (Pais et al., 1997). It possesses several advantages over traditional elution chromatography, namely, overcoming problems associated with solid handling, efficient utilization of adsorbent, continuous mode of operation, lowering eluent consumption in reducing downtime

Correspondence to: Ajay K. Ray as separation and regeneration take place concurrently, allows for the possibility of scaling up to a large-scale production unit due to simplicity in the mechanical design, etc. (Ray et al., 1994).

The trend of the pharmaceutical sector towards commercializing the chiral drugs as pure enantiomers enhances the need of efficient processes for the separation of racemates. In the beginning of the 1990s, it was shown that significant benefits in terms of the chiral phase and the eluent consumption could be achieved by performing the separation based on SMB technology (Rekoske, 2001). Consequently, in a relatively short time, the separation of pharmaceutical compounds began to be performed using the SMB technology, particularly after the recent developments in Chiral Stationary Phases (CSPs) and nonlinear chromatography theory (Guiochon et al., 1994).

The Simulated Moving Bed process is a practical implementation of the True Moving Bed (TMB) process in which the countercurrent movement between the mobile phase and the stationary phase in TMB is simulated by moving the input/output ports periodically and in tandem along a series of fixed columns in the direction of the mobile-phase flow, while holding the bed stationary. Hence, periodic discrete steps in the SMB replace the continuous motion of the fluid and solid in the TMB. In the Varicol operation (Ludemann-Hombourger et al., 2000, 2002), although the switching period is decided a priori and kept constant, a nonsynchronous shift of the inlet and outlet ports is employed within a (global) switching period. During one global switching period, there are different column configurations for sub-time intervals due to local switching. Given the total number of columns employed in a Varicol process, the number of columns in each zone varies with time within a global switching period. As a result, the Varicol process can have several column configurations, which endow more flexibility compared to the conventional SMB process. The Varicol process, which does not require any additional cost, is more flexible compared to the traditional SMB process, which can be regarded as the most rigid and a special case of the Varicol process. 
Process industries aim at maximizing their production capacities while simultaneously improving the product quality and reducing operating costs. Usually, there exists a tradeoff between these requirements. This is particularly true in chiral separation using the SMB (and Varicol system) system where purities of the products are crucial and have to satisfy relatively narrow specifications. Thus, the design and operation of SMB systems (Charton and Nicoud, 1995) need to be optimized using multiple objective functions and constraints, which are often conflicting (Bhaskar et al., 2000). Quite a few studies have been reported in the open literature on the optimization of SMB systems (Dünnebier and Klatt, 1999; Dünnebier et al., 2000; Mazzotti et al., 1997; Storti et al., 1995; Strube et al., 1999; Wu et al., 1999). Except for the works of Zhang et al. (2002a, 2002b), all the other investigations are based on single objective optimization, incorporating several objectives with some weight factors. This parametric approach is not efficient and also has the drawback of possibly losing certain optimal solutions when the nonconvexity of the objective function gives rise to a duality gap (Deb, 2001), something that is very difficult to ensure for more complex, real-life problems.

In multiobjective optimization, there may not exist a solution that is the best (global optimum) with respect to all objectives. Instead, there could exist an entire set of optimal solutions that are equally good, known as the Pareto-optimal solutions. A Pareto set is defined such that when one moves from one point to another, at least one objective function improves and at least one other worsens. So, no point on this curve is superior to any other solution. The choice of a solution over the other solutions requires additional knowledge of the problem, and often this knowledge is intuitive and nonquantifiable. The Pareto-set narrows down the choices and helps to guide a decision-maker in selecting a desired operating point (called the preferred solution) from among the (restricted) set of Pareto-optimal points, rather than from a much larger number of possibilities (Bhaskar et al., 2000).

The state-of-the-art optimization algorithm, the Genetic Algorithm (Holland, 1975) is used in this study. The algorithm mimics the process of natural selection and natural genetics. The Darwinian principle of "survival of the fittest" is used to generate improved solutions (Deb, 2001). The sorting and sharing mechanism introduced in Elitist Non-dominated Sorting Genetic Algorithm, NSGA-II (Deb et al., 2002), has paved the way for multiobjective optimization. The recent modification with jumping genes (Kasat et al., 2002) has improved the diversity of hypothetic mating pool leading to a much better spreading of solution at increased convergence speed. The jumping gene operations adapt a modified mutation operator, borrowing from the concept of jumping genes in natural genetics. Kasat et al. (2002) used NSGA-II-JG for the optimization of an industrial fluid catalytic cracking unit and reported Pareto optimal solutions in significantly less number of generations. Recently, Nandasana et al. (2003) reviewed applications of different adaptations of NSGA in chemical engineering. A short note on the optimization technique used is given in the Appendix.

A thorough and comprehensive optimization study on the performance of the SMB and Varicol processes have been studied in finding the best operating conditions for the enantioseparation of SB-553261 racemate. An existing model that can predict published pilot-scale experimental results of the system is used in the optimization. The model was verified first with published experimental results (Ludemann-Hombourger et al., 2002), which was followed by single objective optimization to see how much improvement can be achieved for the existing SMB and Varicol system. Thereafter, few multiobjective optimization studies were carried out to obtain the Pareto-optimal solutions to provide a clear distinction between the performances of the SMB and the Varicol process.

\section{THE SIMULATED MOVING BED AND THE VARICOL PROCESS}

A SMB unit consists of an array of several fixed bed columns with flexible valve injection and withdrawal ports (see Fig. 1). The countercurrent contact between the fluid and the solid phase is mimicked by synchronous shifting of injection and withdrawal ports in the direction of fluid phase at a predetermined shifting interval, known as switching time. The separation of components in SMB is primarily due to the difference in adsorption affinity towards the stationary bed of adsorbent. The difference in selectivity enables at least two components to be separated and collected at the respective terminal port at high purity. The key elements in the SMB separation include the selection of appropriate adsorbent and internal flow rates. Comprehensive studies emphasizing the importance of adsorbent selection to achieve the maximum throughput (Schulte et al., 1997) and the flow rates setting to ensure that every zone might assume its specific role (Kawase et al., 1996) have been reported.

The simulated moving bed technique as a unique separation process can be tailored into several zone configurations adapting to a certain condition and/or requirement. While the four-zone SMB is the most commonly used practice, the three-zone distribution (Bjorklund et al., 2001) can be employed to process a product that has absolutely no or little affinity toward the adsorbent. In this case, zone IV (as depicted in Fig. 1), whose main task is to prevent the less retained component from entering zone $\mathrm{I}$, is no longer needed. Another criteria for adopting three-zone SMB is the low economical value of the desorbent as its demand will increase due to the absence of zone IV. A five-zone SMB is specifically designed when a third component is present that could either be the most or the least retained component. The fifth zone acts either as adjoining secondary raffinate recovery column (in the case of the third fraction be the least retained component) or an additional extract recovery column (in the case of the third fraction be the most retained component) eluted with secondary 


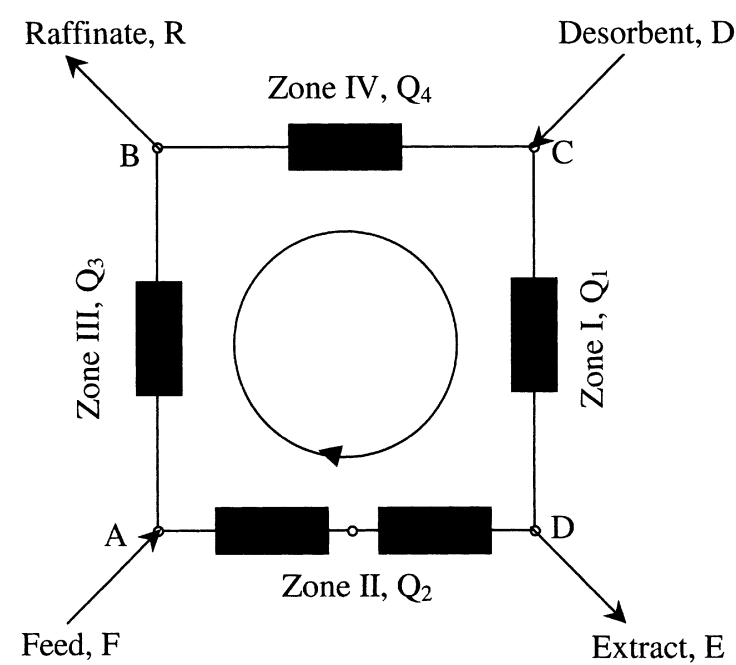

(a)
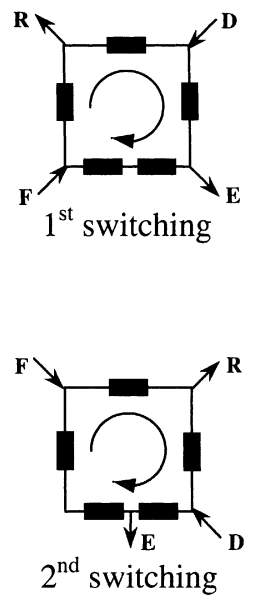

(b)

Figure 1. (a) Schematic diagram of four-zone five-column SMB process with column configuration 1/2/1/1; (b) Port switching sequence of SMB process.

desorbent line. Ultimately, ternary SMB, which is equivalent to the TMB process, is used for the treatment of multicomponent separation.

Another approach in improving the performance of SMB is the Varicol process (Ludemann-Hombourger et al., 2000). The column configuration in Varicol process varies over a sub-time interval as the terminal ports are unequally shifted during one global shifting period. The switching time $t_{s}$, which is related directly to the solid flow rate in SMB, is also a key parameter in the Varicol process, although the relationship is not straightforward. In Varicol operation, a nonsynchronous shift of the inlet and outlet ports is usually employed within a global switching period, which is again kept constant in time. Within a global switching period, $t_{s}$, the column configuration is allowed to alter for each quarter of $t_{s}$ for a four-subinterval operation. Pseudo-solid velocity is not constant as in the SMB process and introducing more sub-time interval in the global switching period can further enhance the net driving force for separation (Zhang et al., 2002a). For example in a five-column set-up, it might happen that zone II requires the extra column at initial subinterval, while in the subsequent time interval, the additional column is required in zone I, IV, and III respectively as shown in Figure 2. The column configuration for the above sequence corresponds to $1 / 2 / 1 / 1\left(0 \approx t_{s} / 4\right)$ to $2 / 1 / 1 / 1$ $\left(t_{s} / 4 \approx t_{s} / 2\right)$ by shifting the extract port by exactly one column in the forward direction, then to $1 / 1 / 1 / 2\left(t_{s} / 2 \approx\right.$ $\left.t_{s} 3 / 4\right)$ by shifting the desorbent port by one column in the forward direction, and finally to $1 / 1 / 2 / 1\left(t_{s} 3 / 4 \approx t_{s}\right)$ by shifting the raffinate port forward by one column. The configuration 1/2/1/1 explicates that there are two columns in zone II, with one column each in zone I, III, and IV, respectively. As a result, in a four-subinterval Varicol process, there are four different column configurations for the four subintervals due to local switching during one global switching period. Hence, the Varicol process allows greater flexibility compared to a conventional SMB process. The number of columns in each zone varies with time within a global switching period, but the number of columns in each zone returns to the starting value at the end of the global switching period. In terms of the time average number of columns per zone this corresponds to 1.25/1.25/1.25/1.25 for the above example. Therefore, locations of input/output ports in a Varicol process are quite different from that of the SMB process. Note that in principle it is possible that a port may shift more than once during one global switching period, either forward or even in a backward direction. As a result, the Varicol process can have several column

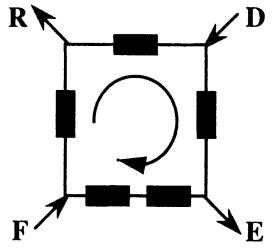

$0 \sim 1 / 4 \mathrm{t}_{\mathrm{s}}$ $1^{\text {st }}$ switching

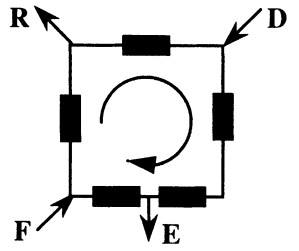

$1 / 4 t_{s} \sim 1 / 2 t_{s}$

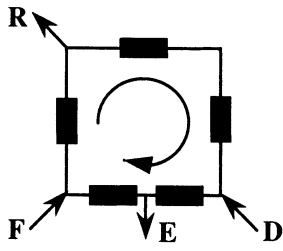

$1 / 2 t_{s} \sim 3 / 4 t_{s}$

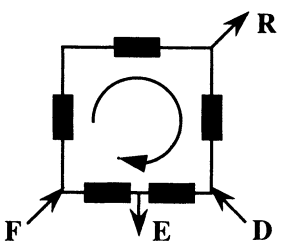

$3 / 4 t_{s} \sim t_{s}$

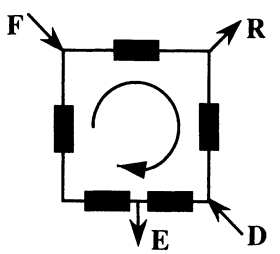

$0 \sim 1 / 4 \mathrm{t}_{\mathrm{s}}$ $2^{\text {nd }}$ switching

Figure 2. Port switching sequence of the four-subtime interval five-column Varicol process. The average number of columns per zone in one global switching period is $1.25 / 1.25 / 1.25 / 1.25$. 
configurations, which allow more flexibility compared to a SMB process. The SMB process can be regarded as a special case of the more flexible Varicol process.

Simulated moving bed chromatography, though a versatile and superior separation technique, has a relatively high capital and operating cost that prevents it from being the ultimate technology. Initially invented in 1950, the use of SMB chromatography was limited only to large-scale production in petrochemical (Broughton and Gerhold, 1961) and food industries (Azevedo and Rodrigues, 2001). This study presents an optimization strategy to overcome the economic limitations of the SMB application in the pharmaceutical industry by focusing on the enantio-separation of SB-553261 racemate. The high requirements of the chiral stationary phase and the mobile phase encourage the need to increase throughput at a certain allowable purity requirement.

\section{THE MATHEMATICAL MODEL AND ITS VERIFICATION}

In the open literature, the only reported results on the Varicol process are those of Ludemann-Hombourger et al. (2000, 2002) for the enantio-separation of 1,2,3,4-tetrahydro-1naphthol and the optical isomers of SB-553261 racemate, using Chiralpak AD $20 \mu \mathrm{m}$ as CSP. Several models are available in the open literature quantifying the behavior of the simulated moving bed chromatographic process. A mixing cell model is used in this work coupled with modified competitive Langmuir adsorption isotherm due to its aptness in high-performance preparative chromatography. The column is assumed as a cascade of ideal mixing cells. The model takes into account mass transfer kinetics and hydrodynamics, which is characterized by the number of theoretical plates. The mass balance equation for component $i$ in mixing cell $k$ during the $N^{\text {th }}$ switching period for SMB:

$$
\begin{aligned}
C_{i, k-1}^{(N)}= & C_{i, k}^{(N)}+\left[\frac{t_{0}(\phi)}{J}\right] \frac{d C_{i, k}^{(N)}}{d t}+\left[\frac{1-\varepsilon}{\varepsilon}\right]\left[\frac{t_{0}(\phi)}{J}\right] \\
& \times \frac{d \bar{C}_{i, k}^{(N)}}{d t} 0 \leq t \leq t_{s}
\end{aligned}
$$

The mass balance equation for component $\mathrm{i}$ in mixing cell $k$ during the $M^{\text {th }}$ subinterval of the $N^{\text {th }}$ switching period for Varicol:

$$
\begin{aligned}
& C_{i, k-1}^{(N, M)}= C_{i, k}^{(N, M)}+\left[\frac{t_{0}(\phi)}{J}\right] \frac{d C_{i, k}^{(N, M)}}{d t}+\left[\frac{1-\varepsilon}{\varepsilon}\right]\left[\frac{t_{0}(\phi)}{J}\right] \\
& \times \frac{d \bar{C}_{i, k}^{(N, M)}}{d t} \\
& 0 \leq t \leq t_{s} / 4 ; M=1,2,3, \text { or } 4
\end{aligned}
$$

where $C$ and $\bar{C}$ are the concentration in the mobile and the stationary phases, respectively, $J$ is the theoretical number of cells in the column, and $t_{0}(\phi)$ is the zero retention time of the column in section $\phi$ (I, II, III, or IV) and is given by

$$
t_{0}(\phi)=\frac{\varepsilon V_{c o l}}{Q(\phi)}
$$

where $Q(\phi)$ is the volumetric flow rate in the column in section $\phi$, and $\varepsilon$ is the column external porosity, used as 0.43 (which was obtained by tuning the model to fit the experimental results). Suitable boundary conditions must be used to properly simulate the process. The boundary conditions change with time due to the periodic operation scheme of the process according to the position of the various process streams.

Initial condition is derived from the fact that the column is empty as the process initializes, then:

$$
C_{i, k}^{(N=0)}=C_{i, k}^{0}=0
$$

The boundary condition is derived from the mass balance at the inlet node of each zone in SMB. The mass balance at the beginning of zone I will give:

$$
\left.C_{i, f i r s t}^{(N)}\right|_{\phi=I}=\frac{\left.\left(Q_{1}-Q_{D}\right) C_{i, l a s t}^{(N)}\right|_{\phi=I V}}{Q_{1}}
$$

The mass balance at the beginning of zone II when the extract product is withdrawn at the end of zone I will give:

$$
\left.C_{i, \text { first }}^{(N)}\right|_{\phi=I I}=\left.C_{i, \text { last }}^{(N)}\right|_{\phi=I}
$$

Fresh feed is injected to the inlet of zone III and the mass balance at the beginning of zone III will give:

$$
\left.C_{i, \text { first }}^{(N)}\right|_{\phi=I I I}=\frac{\left.Q_{I I} C_{i, \text { last }}^{(N)}\right|_{\phi=I I}+Q_{F} C_{i}^{F}}{Q_{I I I}}
$$

\begin{tabular}{|c|c|c|}
\hline Column dimension & 10-mm ID and $81-\mathrm{mm}$ bed length & \\
\hline Feed concentration & $C_{F 1}=C_{F 2}=32$ & $(g / L)$ \\
\hline \multirow[t]{2}{*}{ Adsorption isotherm } & $\bar{C}_{1}=1.35 \cdot C_{1}+\frac{0.294 \cdot C_{1}}{1+0.0338 \cdot C_{1}+0.1696 \cdot C_{2}}$ & $(g / L)$ \\
\hline & $\bar{C}_{2}=1.17 \cdot C_{2}+\frac{1.509 \cdot C_{2}}{1+0.0338 \cdot C_{1}+0.1696 \cdot C_{2}}$ & \\
\hline Pressure drop/column & $\Delta \mathrm{P} / \mathrm{L}=2.5 \cdot 10^{9} \cdot \mathrm{u}$ & (SI Unit) \\
\hline Column efficiency & $\begin{array}{l}\mathrm{H}_{1}=6 \cdot 10^{-5}+1.63 \cdot 10^{-3} \cdot \mathrm{u} \\
\mathrm{H}_{2}=6 \cdot 10^{-5}+2.64 \cdot 10^{-3} \cdot \mathrm{u}\end{array}$ & $\begin{array}{l}\text { (SI Unit) } \\
\text { (SI Unit) }\end{array}$ \\
\hline
\end{tabular}

The mass balance at the beginning of zone IV when raffinate product is withdrawn at the end of zone III will give

$$
\left.C_{i, \text { first }}^{(N)}\right|_{\phi=I V}=\left.C_{i, \text { last }}^{(N)}\right|_{\phi=I I I}
$$

The relevant experimental conditions are tabulated in Table I. The number of theoretical plates of 120 is derived

Table I. Column dimension, feed composition, adsorption isotherm, and column hydrodynamics used in the optimization studies. ${ }^{\text {a }}$

${ }^{\mathrm{a}}$ Ludemann-Hombourger et al., 2002. 
from the single column experiment. The resulting firstorder differential equations were solved using DIVPAG (based on Gear's algorithm) in IMSL library. Some important process performance parameters applied in this study are

$$
\begin{gathered}
\text { Pur }=100 \cdot \frac{\left.\int_{0}^{t_{s}} C_{i, \phi}^{(N)}\right|_{z=L} d t}{\left.\int_{0}^{t_{s}} \sum_{i=R, S} C_{i, \phi}^{(N)}\right|_{z=L} d t} \\
\operatorname{Pr}=\left.\left(Q_{\phi}-Q_{\phi+I}\right) \int_{0}^{t_{s}} C_{i, \phi}^{(N)}\right|_{z=L} d t \\
\operatorname{Rec}=100 \times \frac{\left.\left(Q_{\phi}-Q_{\phi+I}\right) \int_{0}^{t_{s}} C_{i, \phi}^{(N)}\right|_{z=L} d t}{Q_{F} C_{i}^{F}} \\
\left.\sum_{D}\left(Q_{\phi}-Q_{\phi+I}\right) \int_{0}^{t_{s}} C_{i, \phi}^{(N)}\right|_{z=L} d t
\end{gathered}
$$

where $i=$ component $-i$ (R-enantiomer for extract product, S-enantiomer for raffinate product), $\phi=$ zone in SMB (I for extract product, III for raffinate product).

The model equation is verified for the same experimental setting as reported in the work of Ludemann-Hombourger et al. (2002) for six-column SMB: $Q_{F}=0.3 \mathrm{~mL} / \mathrm{min}, Q_{1}=$ $15.3 \mathrm{~mL} / \mathrm{min}, Q_{D}=8.55 \mathrm{~mL} / \mathrm{min}, Q_{E}=7.06 \mathrm{~mL} / \mathrm{min}, Q_{R}=$ $1.79 \mathrm{~mL} / \mathrm{min}$, and $t_{s}=1.11 \mathrm{~min}$ and the result can be seen in Figure 3 where nearly all simulated points somewhat agree with the experimental points. It should be noted that best values of $\varepsilon$ and NTP were obtained by tuning (minimizing least square error between experimental and model predicted values) using the genetic algorithm. This

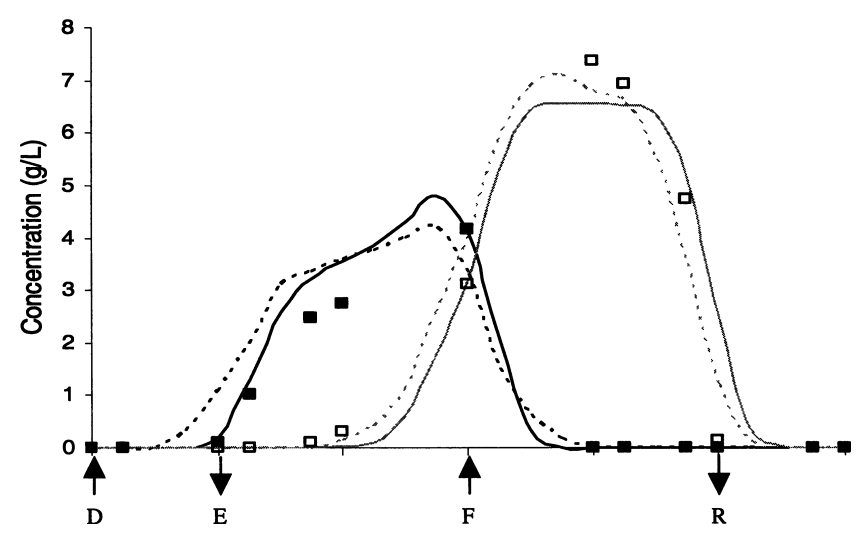

Figure 3. Experimental and simulated concentration profiles for a sixcolumn SMB. Grey: S-enantiomer; black: R-enantiomer; symbol: experiment (Ludemann-Hombourger et al., 2002); dashed line: simulation (Ludemann-Hombourger et al., 2002); solid line: simulation (this work). Reference values: $Q_{1}=15.3 \mathrm{~mL} / \mathrm{min}, Q_{F}=0.3 \mathrm{~mL} / \mathrm{min}, Q_{D}=$ $8.55 \mathrm{~mL} / \mathrm{min}, Q_{E}=7.06 \mathrm{~mL} / \mathrm{min}, Q_{R}=1.79 \mathrm{~mL} / \mathrm{min}$, and $t_{s}=1.11 \mathrm{~min}$, $L_{c o l}=8.1 \mathrm{~cm}, \chi=1 / 2 / 2 / 1$. setting, however, served merely as a verification tool and was not subsequently used either in sensitivity analysis or in the optimization study. We have used the experimental conditions of five-column Varicol $\left(Q_{1}=17.49 \mathrm{~mL} / \mathrm{min}\right)$ as the reference conditions to compare the performance of four-column Varicol, five-column SMB, and five-column Varicol. In addition, the high recovery reported for a fivecolumn Varicol experiment indicates the ease of performing the experiment at the given setting, and it will therefore help as an experimental verification towards the optimization result obtained in this work. Hence, the model is further verified at this setting and the result is reported in Table II. Note that the simulation result is somewhat different from the experimental result since all details about the fivecolumn experimental configuration were not reported by Ludemann-Hombourger et al. (2002). The closest possible column configuration $(1 / 1.75 / 1.5 / 0.75)$ is the one we have used and reported in Table II. The number of columns in each zone varies with time within a global switching period, but the number of columns in each zone returns to the starting value at the end of the global switching period. Note that the average number for any particular zone is obtained as follows: For example, for zone II, 1.75 is obtained from $(2+2+2+1) / 4$, where the numbers in the bracket is the number of columns in zone II in the four-subintervals. The model is used as a tool both to predict the behavior of the system as well as to find the optimal operating condition of the process.

\section{Sensitivity Analysis}

To determine the sensitivity and complex interplay of the operating parameters (such as switching time, desorbent and raffinate flow rates, etc.) on the performance of the system (in terms of purity and productivity of raffinate and

Table II. Comparison of process performance for five-column, foursubinterval Varicol process.

\begin{tabular}{lcc}
\hline \multicolumn{1}{c}{ Process parameter } & Reference $^{\mathrm{a}}$ & This work \\
\hline$Q_{l}(\mathrm{~mL} / \mathrm{min})$ & \multicolumn{2}{c}{17.49} \\
$Q_{E}(\mathrm{~mL} / \mathrm{min})$ & 7.59 & \\
$Q_{F}(\mathrm{~mL} / \mathrm{min})$ & 0.3 & \\
$Q_{D}(\mathrm{~mL} / \mathrm{min})$ & \multicolumn{2}{c}{9.78} \\
$t_{s}(\mathrm{~min})$ & 0.925 \\
$L_{c o l}(\mathrm{~cm})$ & \multicolumn{3}{c}{8.1} & \\
$\chi$ & $0.95 / 1.85 / 1.5 / 0.7$ & $1 / 1.75 / 1.5 / 0.75^{\mathrm{b}}$
\end{tabular}

Calculated parameter

$\begin{array}{lcr}\operatorname{PurR}(\%) & 99.7 & 99.988 \\ \operatorname{PurE}(\%) & 96.8 & 99.057 \\ \operatorname{Rec} R(\%) & 96.8 & 99.697 \\ \operatorname{Rec} E(\%) & 99.9 & 98.598 \\ \operatorname{Pr}\left(\mathrm{g}_{\text {product }} / \mathrm{d}\right) & 13.413 & 13.706 \\ \operatorname{SC}\left(\mathrm{m}_{\text {desorbent }}^{3} / \mathrm{kg}_{\text {product }}\right) & 1.05 & 1.028\end{array}$

${ }^{a}$ Ludemann-Hombourger et al., 2002.

${ }^{\mathrm{b}}$ Varicol switching sequence: $1 / 2 / 1 / 1,1 / 2 / 1 / 1,1 / 2 / 2 / 0,1 / 1 / 2 / 1$. 
extract streams) sensitivity analysis was carried out for a five-column SMB. Sensitivity analysis is required as it not only shows which parameters are more sensitive for this particular system but also helps to decide the bounds for the decision variables. Otherwise, one may be searching for optimal solutions in a parameter space in which global optimal solution is not present. Moreover, each optimization run involving multiple objectives is very time consuming as more than 2500 simulations need to be performed and in each simulation one must switch sufficient number of times to reach steady state before calculating the system performance parameters. The effect of switching time, $t_{s}$, on purity (Pur) and productivity (Pr) of the raffinate and extract streams is shown in Fig. 4(a) and 4(b). With the increase of switching time, residence time increases and hence PrR increases but $\operatorname{PrE}$ decreases due to dilution by $Q_{D}$. The purity tends to increase from $t_{s}=0.8 \mathrm{~min}$ to $1 \mathrm{~min}$ and subsequently decreases. The behavior of purity below and beyond $t_{s}=1 \mathrm{~min}$ can be easily understood if the relative velocity of the two components to be separated are considered. The countercurrent separation of the components is achieved by appropriately specifying the internal flow rates in the columns and the switching time. Petroulas et al. (1985) defined for true countercurrent moving bed chromatographic reactor $(\mathrm{CMCR})$ a parameter, $\sigma_{i}$, called relative carrying capacity of the solid relative to the fluid stream for any component $i$ as

$$
\sigma_{i}=\frac{1-\varepsilon}{\varepsilon} N K_{i} \frac{u_{s}}{u_{g}}=\delta_{i} \frac{u_{s}}{u_{g}}
$$

where $u_{s}$ and $u_{g}$ are respectively solid-phase and fluidphase velocity. They showed that to achieve countercurrent
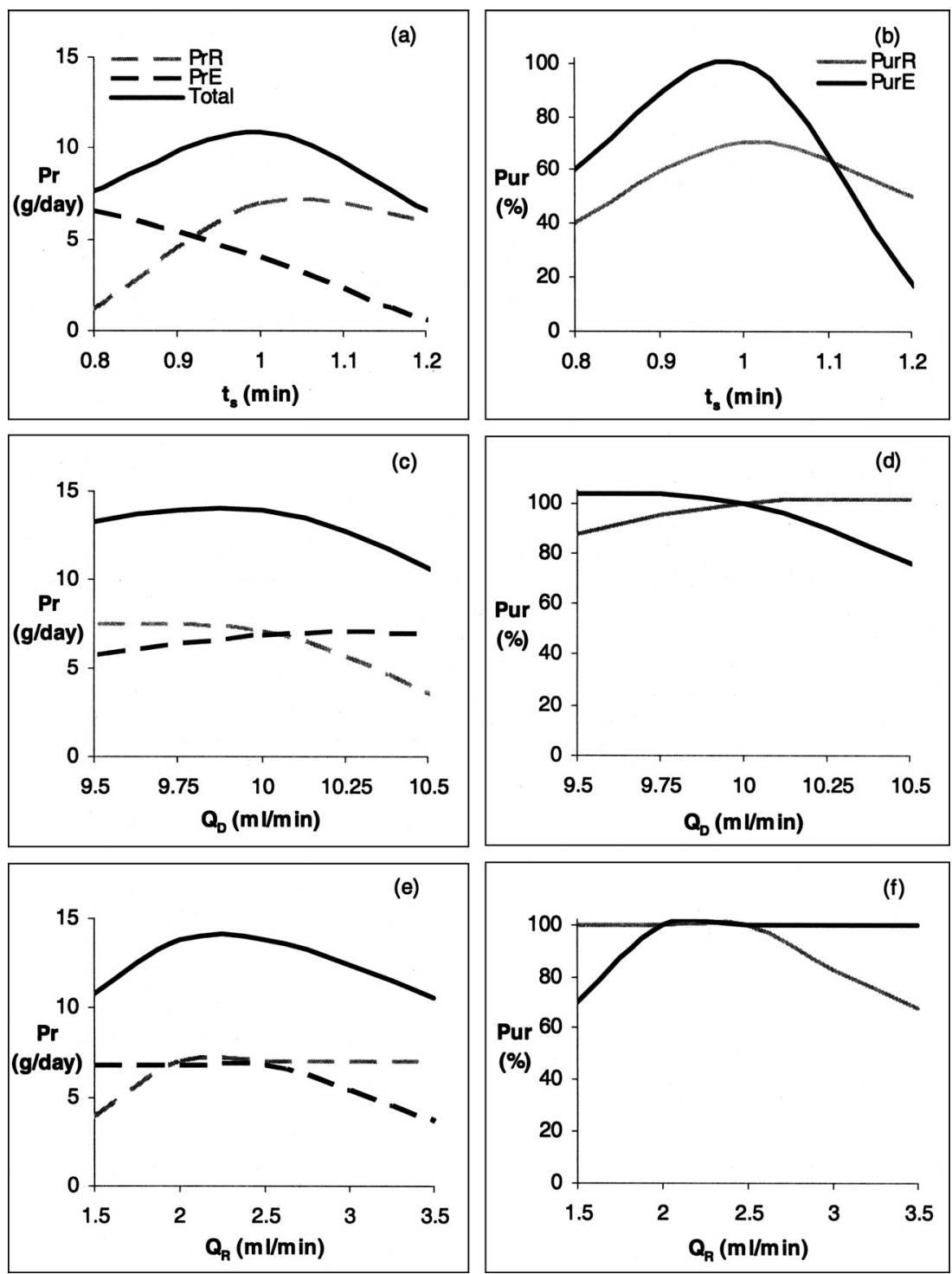

Figure 4. Effect of decision variables $\left(t_{s}, Q_{D}\right.$, and $\left.Q_{R}\right)$ on Productivity $(P r)$ and Purity (Pur) of raffinate and extract streams for a five-column SMB. (Reference value: $Q_{1}=17.49 \mathrm{~mL} / \mathrm{min}, Q_{F}=0.3 \mathrm{~mL} / \mathrm{min}, Q_{D}=10 \mathrm{~mL} / \mathrm{min}, Q_{R}=2.5 \mathrm{~mL} / \mathrm{min}, L_{c o l}=8.1 \mathrm{~cm}, \chi=1 / 2 / 1 / 1$ ). 
separation between the two components, one must set $\sigma$ greater than 1 for one (species move with the solid phase) and less than 1 (species move with the fluid phase) for the other. When $\sigma=0$, it represents fixed bed. Ray et al. (1994) redefined the above parameter, $\sigma$, by replacing the solidphase velocity, $u_{s}$, in CMCR by a hypothetical solid phase velocity, $\zeta$, defined as $\zeta=L_{c o l} / t_{s}$. They found, both theoretically (Ray et al., 1994) and experimentally (Ray and Carr, 1995), that simulation of the countercurrent movement between two components can be achieved when redefined $\sigma$ 's were set such that it is greater than 1 for one and less than 1 for the other component. It was observed that for the reference run, countercurrent separation occurs $(\sigma>1$ for one component and $\sigma<1$ for the other) around $t_{s}$ equal to 1 , while both components travel co-currently $\left(\sigma>1\right.$ for $t_{s}<$ $1 \mathrm{~min}$ and $\sigma<1$ for $t_{s}>1 \mathrm{~min}$ ) spoiling the separation and thereby, the purity.

Figure 4(c) and 4(d) indicate that highest purity for both streams can be achieved when the desorbent flow rate is about $10 \mathrm{~mL} / \mathrm{min}$. This trend is further comprehended when the effect of desorbent flow rates on the steady-state concentration profiles are observed (see Fig. 5). When desorbent flow rate is less than $10 \mathrm{~mL} / \mathrm{min}$, the strongly adsorbed component is not completely washed out of zone I. Moreover, since $Q_{1}$ is fixed, $Q_{4}$ (which increases $\sigma$ ) and hence species move more with the solid phase, thereby decreasing raffinate purity. When the desorbent flow rate is greater than that is required for purging, it will simply lower the extract purity. Extract productivity will increase as the desorbent flow rate increases, but raffinate productivity will decrease as some of the less retained component is lost in the extract withdrawal port.

Figure 4(e) and 4(f) show the effect of raffinate flow rate, $Q_{R}$, on purity and productivity of both the components. Any increase in raffinate flow rate beyond a certain point will reduce the raffinate purity and alternately, increase the extract purity. Figure 6 shows the steady-state concentration profiles inside the columns. At lower raffinate flow rates, $Q_{R}=1.5 \mathrm{~mL} / \mathrm{min}$, the raffinate concentration is high. Although some portions of less retained component appear in the extract withdrawal port, but no trace of the more retained component is found near the raffinate withdrawal port. This explains the high raffinate purity and low extract purity at lower raffinate flow rate. The reduction of liquid flow rates in Sections II and III causes the more retained component to be selectively adsorbed in zone IV, thereby instigating mobile phase concentration build-up of the less retained component in zone IV. This concentration is high enough to be transferred from zone IV to zone I due to recycle, and subsequently, appear in the extract withdrawal port polluting the extract product. Raffinate productivity is low at this point but gradually increases up to a fixed value with the increase of raffinate flow rate. However, the extract productivity decreases as some of the more retained component appears in the raffinate withdrawal port due to increasing raffinate purity.
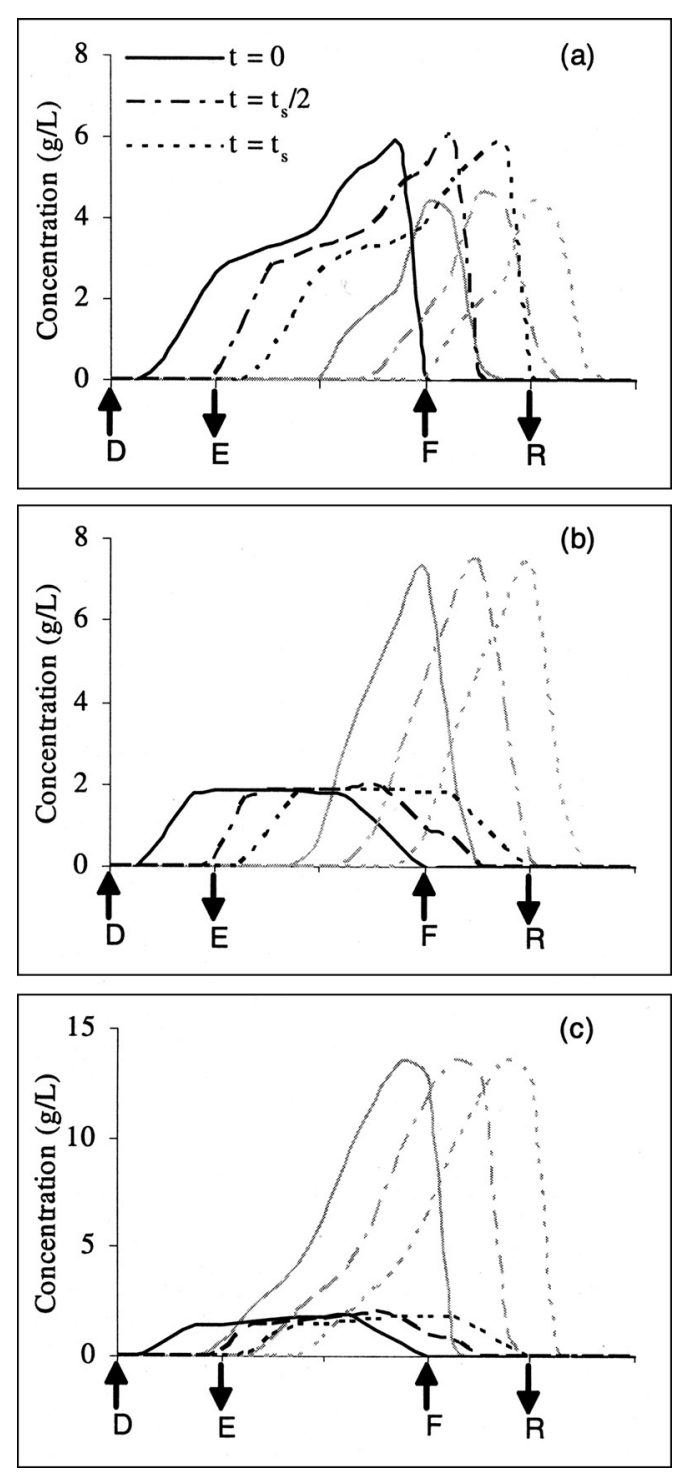

Figure 5. Effect of desorbent flow rate $\left(Q_{D}\right)$ on steady-state concentration profile for a five-column SMB system. (a) $Q_{D}=9.5 \mathrm{~mL} / \mathrm{min}$, (b) $Q_{D}=10 \mathrm{~mL} / \mathrm{min}$, (c) $Q_{D}=10.5 \mathrm{~mL} / \mathrm{min}$. (grey: S-enantiomer, black: R-enantiomer). Reference value: $Q_{1}=17.49 \mathrm{~mL} / \mathrm{min}, Q_{F}=0.3 \mathrm{~mL} / \mathrm{min}$, $Q_{R}=2.5 \mathrm{~mL} / \mathrm{min}, L_{c o l}=8.1 \mathrm{~cm}, \chi=1 / 2 / 1 / 1$.

\section{Optimization of SMB and Varicol Processes}

\section{Case 1. Single-Objective Optimization: Maximization of Throughput}

In general, purity will decrease as feed flow rate is increased making the separation task much more difficult. To test whether the feed flow rate can be increased without jeopardizing the purity requirement, and to test the optimization procedure based on GA, we first solved the following optimization problem:

$$
\operatorname{Max} \quad I=Q_{F}\left[Q_{F}, Q_{R}, t_{s}, \chi\right]
$$

Subject to PurR and PurE $\geq$ Experimental value

(in Ludemann-Hombourger et al., 2002) 

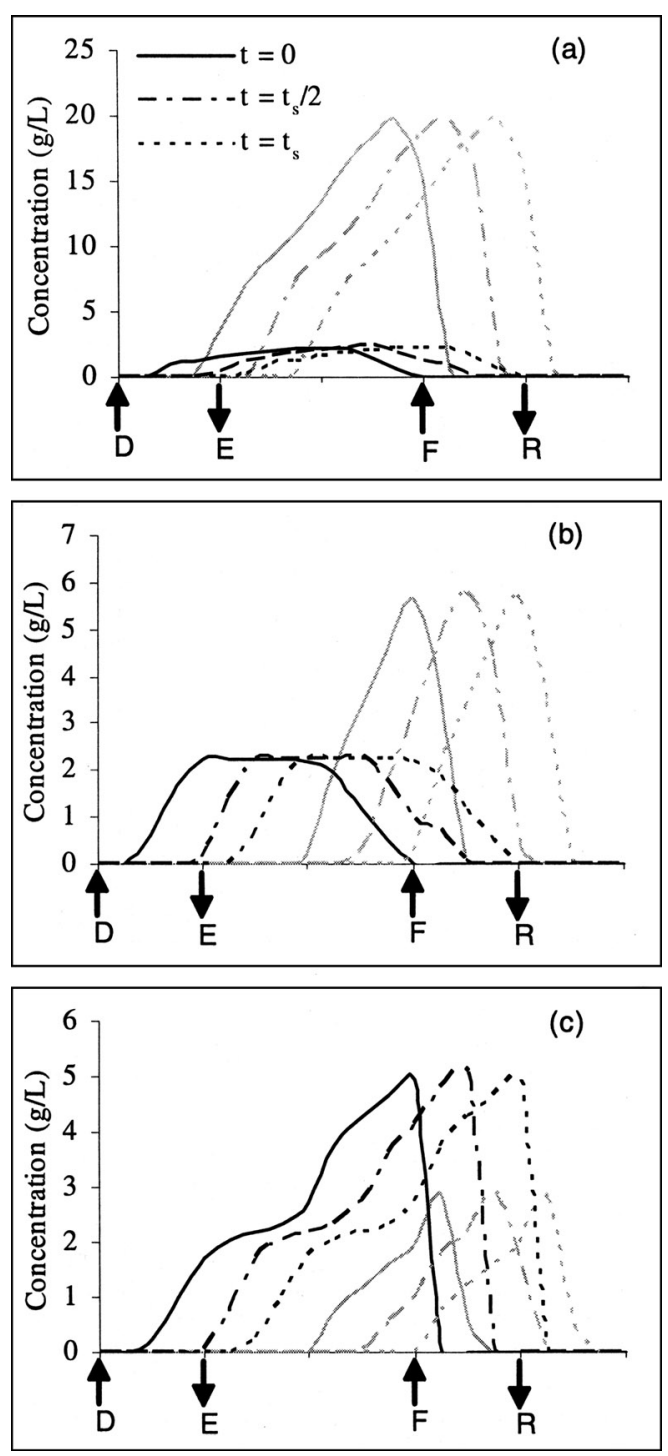

Figure 6. Effect of raffinate flow rate on steady-state concentration profile on a five-column SMB. (a) $Q_{R}=1.5 \mathrm{~mL} / \mathrm{min}$, (b) $Q_{R}=2.5 \mathrm{~mL} / \mathrm{min}$, (c) $Q_{R}=3.5 \mathrm{~mL} / \mathrm{min}$ (grey: S-enantiomer, black: R-enantiomer). Reference value: $Q_{1}=17.49 \mathrm{~mL} / \mathrm{min}, Q_{F}=0.3 \mathrm{~mL} / \mathrm{min}, Q_{D}=10 \mathrm{~mL} / \mathrm{min}$, $L_{c o l}=8.1 \mathrm{~cm}, \chi=1 / 2 / 1 / 1$.

The objective function chosen is maximization of the feed flow rate, $Q_{F}$, subject to target purities of extract, PurE and raffinate, PurR streams greater than experimental reported values by Ludemann-Hombourger (2002). Four decision variables were used for this optimization study as indicated in Eq. (14): feed flow rate, $Q_{F}$, raffinate stream flow rate, $Q_{R}$, switching time, $t_{s}$ and column configuration, $\chi$. To be able to compare our results with those of Ludemann-Hombourger et al. (2002), we solved four cases (see Table III) corresponding to the experimental values for flow rates $Q_{1}$ and $Q_{D}$ used in their work with respect to sixcolumn SMB and four-, five-, and six-columns Varicol, respectively. Since only four flow rates could be selected independently, while the other four are determined by mass balance equations at points A-D (see Fig. 1), the remaining two flow rates (in this case, $Q_{F}$ and $Q_{R}$ ) were used as decision variables. The third decision variable is the switching time $t_{s}$, which clearly has a strong influence on the purity of the outlet streams (see Fig. 4). The bounds for $t_{s}$ lie between the breakthrough times of the two components for a specific CSP.

The fourth decision variable used is the column configuration $(\chi)$. For a fixed number of total columns $\left(N_{c o l}\right)$, there exist a number of possible column configurations (distribution). In a SMB system, there is only one column configuration, which is fixed with time. However, in a Varicol process there are many possible column configurations depending on the number of subtime intervals. To somehow restrict this variety, we consider here only foursubtime interval Varicol process, assuming that in each subinterval the unit can take any one of the configurations possible for the SMB unit as listed in Table IV. For example, for a five-column SMB process, $\chi=J$ indicates the column configuration $1 / 2 / 1 / 1$. Whereas, for a four-subinterval fivecolumn Varicol process, $\chi=\mathrm{I}-\mathrm{J}-\mathrm{I}-\mathrm{K}$ indicates that the sequence of column configurations I-J-I-K was used within the four-subinterval global switching period (see Table IV). In terms of time average column lengths, this corresponds to the configuration 1.25/1.25/1.5/1. The optimization formulation, the bounds of the decision variables, constraints, and the fixed parameter values used are summarized in Table III. To get meaningful optimum solutions, the bounds for the decision variables were estimated using equilibrium theory (Mazzotti et al., 1997; Storti et al., 1995) and the sensitivity analysis of the model.

Table III. Single objective optimization problems solved in this study.

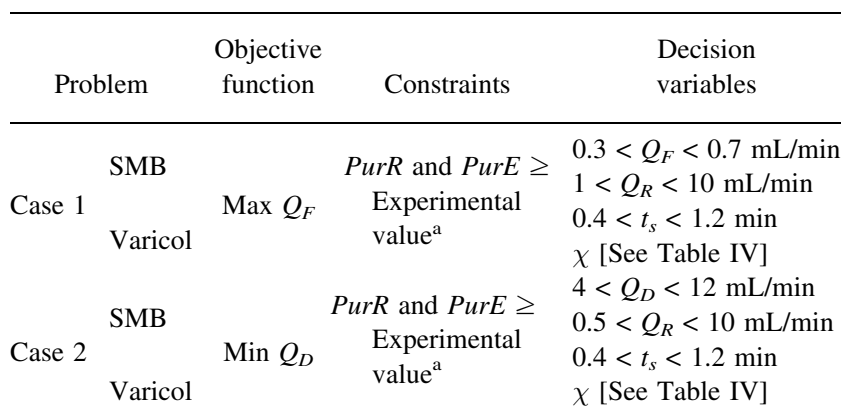

Fixed variables: $L_{c o l}=8.1 \mathrm{~cm}$

$$
\begin{array}{cc}
\text { a } & N_{c o l}=4, \\
& Q_{1}=21.3 \mathrm{~mL} / \mathrm{min} \\
\text { b } & N_{c o l}=5, \\
& Q_{1}=17.5 \mathrm{~mL} / \mathrm{min} \\
\text { c } & N_{c o l}=6, \\
& Q_{1}=15.3 \mathrm{~mL} / \mathrm{min} \\
\text { d } & N_{c o l}=6, \\
& Q_{1}=15.3 \mathrm{~mL} / \mathrm{min}
\end{array}
$$

${ }^{a}$ Ludemann-Hombourger et al., 2002. 
Table IV. Possible optimum column configurations (distribution) for different $N_{c o l}$.

\begin{tabular}{ccccc}
\hline$N_{c o l}$ & $\chi$ & Column configuration & $\chi$ & Column configuration \\
\hline & $\mathrm{A}$ & $0 / 1 / 2 / 1$ & $\mathrm{E}$ & $1 / 2 / 1 / 0$ \\
4 & $\mathrm{~B}$ & $0 / 2 / 1 / 1$ & $\mathrm{~F}$ & $2 / 0 / 1 / 1$ \\
& $\mathrm{C}$ & $1 / 1 / 1 / 1$ & $\mathrm{G}$ & $2 / 1 / 1 / 0$ \\
& $\mathrm{D}$ & $1 / 1 / 2 / 0$ & & \\
& & & & \\
5 & $\mathrm{H}$ & $1 / 1 / 1 / 2^{\mathrm{a}}$ & $\mathrm{J}$ & $1 / 2 / 1 / 1$ \\
& $\mathrm{I}$ & $1 / 1 / 2 / 1$ & $\mathrm{~K}$ & $2 / 1 / 1 / 1$ \\
& & & & \\
& $\mathrm{~L}$ & $1 / 1 / 1 / 3$ & $\mathrm{Q}$ & $1 / 3 / 1 / 1$ \\
6 & $\mathrm{M}$ & $1 / 1 / 3 / 1$ & $\mathrm{R}$ & $2 / 1 / 1 / 2$ \\
& $\mathrm{~N}$ & $1 / 1 / 2 / 2$ & $\mathrm{~S}$ & $2 / 1 / 2 / 1$ \\
& $\mathrm{O}$ & $1 / 2 / 2 / 1$ & $\mathrm{~T}$ & $2 / 2 / 1 / 1$ \\
& $\mathrm{P}$ & $2 / 1 / 1 / 2$ & & \\
\hline
\end{tabular}

${ }^{\mathrm{a} C}$ Column configuration 1/1/1/2 means there is one column in each of the sections I-III and two columns in section IV.

\section{Case 2. Single-Objective Optimization: Minimization of Desorbent Flow Rate}

To reduce operating costs, minimization of desorbent flow rate was selected as the objective function. Desorbent is needed in chromatographic column to desorb (purge) the strongly adsorbed component and it has significant impact on purity of the extract stream. It is desirable to see how far the desorbent requirement can be reduced (thereby reducing operating costs) without sacrificing the required purity. Hence, we solved the following optimization problem:

$$
\operatorname{Max} \quad I=Q_{D}\left[Q_{D}, Q_{R}, t_{s}, \chi\right]
$$

Subject to PurR and PurE $\geq$ Experimental value

(in Ludemann-Hombourger et al., 2002)

Once again, the same four decision variables were used as in case I except $Q_{D}$ is a decision variable in this case while $Q_{F}$ is fixed (see Table III). Yet again, we considered four cases (see Table III) corresponding to the experimental values of flow rates $Q_{1}$ and $Q_{F}$ used in the work of LudemannHombourger et al. (2002) with respect to six-column SMB and four-, five-, and six-columns Varicol, respectively.

Table V compares the optimum results obtained with GA for both cases 1 and 2 with that of the experimental results of Ludemann-Hombourger et al. (2002). It can be seen that the GA optimization leads to a larger feed flow rate (for case 1) and smaller desorbent flow rate (for case 2) for six-column SMB and four-, five-, and six-columns Varicol compared to the reported results. The table also lists the optimum values of $Q_{R}, t_{s}$, and column configuration $(\chi)$ as well as calculated values of extract flow rate $\left(Q_{E}\right)$, product purity (Pur), recovery $(R e c)$, yield $(Y)$, and solvent consumption $(S C)$. From the Table V it can be seen that optimization leads to an optimum $Q_{F}=0.56 \mathrm{~mL} / \mathrm{min}$, an increase of $86 \%$ over the experimental $Q_{F}$ of 0.3 for the four-column Varicol system. Similarly, when desorbent flow rate $\left(Q_{D}\right)$ is minimized, an optimum $Q_{D}=8.1 \mathrm{~mL} / \mathrm{min}$ was obtained, a decrease of $38 \%$ over the experimental $Q_{D}$ of 13.06 for the four-column Varicol system. An average improvement of about $55 \%$ in the amount of feed (throughput) can be handled while about $30-40 \%$ savings of desorbent requirement (although not simultaneously) without sacrificing product purities. It is observed that the optimum switching time for the Varicol process is smaller than that of SMB. Varicol offers more flexibility, and therefore, does not require long residence time as in SMB. The optimum column distribution $(\chi)$ for the four-column Varicol process is $\chi=\mathrm{A} / \mathrm{D} / \mathrm{D} / \mathrm{E}$ (which corresponds to $0.75 / 1.25 / 1.75 / 0.25$ ) for case 1 , while $\chi=\mathrm{C}$ / $\mathrm{C} / \mathrm{D} / \mathrm{F}(\equiv 1.25 / 0.75 / 1.25 / 0.75)$ for case 2. It shows that more columns are needed in zone 3 for case 1 and in zone 1 for case 2. Table $\mathrm{V}$ also reveals that improvement in Varicol over SMB is more obvious when the total number of columns is less, which imparts that Varicol offers more flexibility at a relatively small number of columns. Note that in Table V, shaded cells represent optimum values and the numbers in bracket for $Q_{F}$ and $Q_{D}$ are percentage improvement over the experimentally reported results.

These comparisons, relative to single-objective optimization problems show the reliability and efficiency of genetic algorithm (GA) in finding optimal operating conditions, which compare well with previous literature results and actually lead to improved values of the objective functions. The unique capabilities and superiority of the GA will clearly appear later when considering multiobjective optimization problems.

\section{Multiobjective Optimization of the SMB and Varicol Processes}

The multiobjective optimization problems emerge when several objectives are entailed and they contradict one another. The fact that one cannot improve a certain performance criteria without sacrificing the other leads to the Pareto optimal solution in which the set of solutions are equally good and nondominating. Numerous multiobjective optimization problems can be formulated and they are vital, particularly in the design of a new system. Table VI presents formulation of three such problems.

\section{Case 3. Multiobjective Optimization: Maximization of Purity and Productivity of Raffinate Product}

The simultaneous maximization of purity and productivity of a raffinate stream for a given feed flow rate is first subject to the constraint that purity of extract stream must be greater than $99 \%$. High product purity is typically an important requirement in drug manufacture although for a binary mixture with a low separation factor $\left(K_{A} / K_{B}<1.15\right)$, the high purity requirement entails high cost and low throughput. In this case the optimal design of SMB and Varicol processes was determined at the design stage. Table VI lists 
Table Va. Single objective optimization results as described in cases 1a and 2a.

\begin{tabular}{|c|c|c|c|c|c|}
\hline \multirow{2}{*}{$\begin{array}{l}\text { Performance } \\
\text { parameter }\end{array}$} & \multicolumn{3}{|c|}{ Four-column Varicol } & \multicolumn{2}{|c|}{ Four-column SMB } \\
\hline & L-H et al., $2002^{\mathrm{a}}$ & Case 1 & Case 2 & Case 1 & Case 2 \\
\hline$Q_{1}(\mathrm{~mL} / \mathrm{min})$ & 21.3 & 21.3 & 21.3 & 21.3 & 21.3 \\
\hline$Q_{F}(\mathrm{~mL} / \mathrm{min})$ & 0.3 & $0.56(+86 \%)$ & 0.3 & $0.46(+53 \%)$ & 0.3 \\
\hline$Q_{D}(\mathrm{~mL} / \mathrm{min})$ & 13.06 & 13.06 & $8.09(-38 \%)$ & 13.06 & $10.11(-23 \%)$ \\
\hline$Q_{R}(\mathrm{~mL} / \mathrm{min})$ & 4.58 & 5.50 & 3.90 & 5.25 & 1.66 \\
\hline$t_{s}(\min )$ & 0.8 & 0.60 & 0.60 & 0.70 & 0.77 \\
\hline$\chi(-)$ & $0.85 / 1.5 / 1.15 / 0.5$ & $\mathrm{~A} / \mathrm{D} / \mathrm{D} / \mathrm{E}$ & $\mathrm{C} / \mathrm{C} / \mathrm{D} / \mathrm{F}$ & $\mathrm{C}$ & $\mathrm{C}$ \\
\hline$Q_{E}(\mathrm{~mL} / \mathrm{min})$ & 8.78 & 8.11 & 4.49 & 8.27 & 6.97 \\
\hline PurR (\%) & 99.6 & 99.85 & 99.75 & 99.98 & 99.99 \\
\hline PurE (\%) & 96.6 & 99.00 & 97.40 & 98.95 & 97.08 \\
\hline$Y\left(\mathrm{~g}_{\text {prod }} / \mathrm{g}_{\mathrm{CSP}} / \mathrm{d}\right)$ & 0.906 & 1.698 & 0.918 & 1.431 & 0.913 \\
\hline $\operatorname{RecR}(\%)$ & 87.8 & 100 & 97.68 & 100 & 97.43 \\
\hline $\operatorname{Rec} E(\%)$ & 99.9 & 98.90 & 98.57 & 98.73 & 97.64 \\
\hline$S C\left(\mathrm{~m}_{\text {desorbent }}^{3} / \mathrm{kg}_{\text {prod }}\right)$ & 1.392 & 0.750 & 0.859 & 0.889 & 1.080 \\
\hline
\end{tabular}

${ }^{\mathrm{a}}$ Ludemann-Hombourger et al., 2002.

Table Vb. Single objective optimization results as described in cases $1 \mathrm{~b}$ and $2 \mathrm{~b}$.

\begin{tabular}{|c|c|c|c|c|c|}
\hline \multirow{2}{*}{$\begin{array}{l}\text { Performance } \\
\text { parameter }\end{array}$} & \multicolumn{3}{|c|}{ Five-column Varicol } & \multicolumn{2}{|c|}{ Five-column SMB } \\
\hline & L-H et al., $2002^{\mathrm{a}}$ & Case 1 & Case 2 & Case 1 & Case 2 \\
\hline$Q_{1}(\mathrm{~mL} / \mathrm{min})$ & 17.5 & 17.5 & 17.5 & 17.5 & 17.5 \\
\hline$Q_{F}(\mathrm{~mL} / \mathrm{min})$ & 0.3 & $0.51(+70 \%)$ & 0.3 & $0.46(+54 \%)$ & 0.3 \\
\hline$Q_{D}(\mathrm{~mL} / \mathrm{min})$ & 9.78 & 9.78 & $5.71(-42 \%)$ & 9.78 & $6.24(-36 \%)$ \\
\hline$Q_{R}(\mathrm{~mL} / \mathrm{min})$ & 2.49 & 4.96 & 1.89 & 2.05 & 0.89 \\
\hline$t_{s}(\min )$ & 0.93 & 0.74 & 0.72 & 0.91 & 0.75 \\
\hline$\chi(-)$ & $0.95 / 1.85 / 1.5 / 0.7$ & $\mathrm{I} / \mathrm{J} / \mathrm{I} / \mathrm{K}$ & $\mathrm{H} / \mathrm{K} / \mathrm{K} / \mathrm{K}$ & $\mathrm{J}$ & $\mathrm{J}$ \\
\hline$Q_{E}(\mathrm{~mL} / \mathrm{min})$ & 7.59 & 5.33 & 4.12 & 8.19 & 5.65 \\
\hline PurR (\%) & 99.7 & 99.94 & 99.83 & 99.97 & 99.94 \\
\hline PurE (\%) & 96.8 & 99.28 & 99.85 & 99.17 & 99.33 \\
\hline$Y\left(\mathrm{~g}_{\text {prod }} / \mathrm{g}_{\mathrm{CSP}} / \mathrm{d}\right)$ & 0.725 & 1.271 & 0.747 & 1.149 & 0.745 \\
\hline $\operatorname{RecR}(\%)$ & 96.8 & 100 & 100 & 100 & 99.83 \\
\hline $\operatorname{RecE}(\%)$ & 99.9 & 98.71 & 99.29 & 98.65 & 99.33 \\
\hline$S C\left(\mathrm{~m}_{\text {desorbent }}^{3} / \mathrm{kg}_{\text {prod }}\right)$ & 1.05 & 0.600 & 0.596 & 0.664 & 0.653 \\
\hline
\end{tabular}

${ }^{\mathrm{a}}$ Ludemann-Hombourger et al., 2002.

Table Vc. Single objective optimization results as described in cases $1 \mathrm{c}$ and 2c.

\begin{tabular}{|c|c|c|c|c|c|}
\hline \multirow{2}{*}{$\begin{array}{l}\text { Performance } \\
\text { parameter }\end{array}$} & \multicolumn{3}{|c|}{ Six-column SMB } & \multicolumn{2}{|c|}{ Six-column Varicol } \\
\hline & L-H et al., $2002^{\mathrm{a}}$ & Case 1 & Case 2 & Case 1 & Case 2 \\
\hline$Q_{1}(\mathrm{~mL} / \mathrm{min})$ & 15.3 & 15.3 & 15.3 & 15.3 & 15.3 \\
\hline$Q_{F}(\mathrm{~mL} / \mathrm{min})$ & 0.3 & $0.43(+44 \%)$ & 0.3 & $0.46(+54 \%)$ & 0.3 \\
\hline$Q_{D}(\mathrm{~mL} / \mathrm{min})$ & 8.55 & 8.55 & $5.57(-35 \%)$ & 8.55 & $5.40(-37 \%)$ \\
\hline$Q_{R}(\mathrm{~mL} / \mathrm{min})$ & 1.79 & 3.39 & 1.39 & 3.23 & 1.57 \\
\hline$t_{s}(\min )$ & 1.11 & 0.89 & 0.87 & 0.90 & 0.83 \\
\hline$\chi(-)$ & $\mathrm{O}$ & $\mathrm{O}$ & $\mathrm{O}$ & $\mathrm{M} / \mathrm{O} / \mathrm{S} / \mathrm{S}$ & N/M/S/S \\
\hline$Q_{E}(\mathrm{~mL} / \mathrm{min})$ & 7.06 & 5.60 & 4.47 & 5.78 & 4.13 \\
\hline PurR (\%) & 99.6 & 99.98 & 99.97 & 100 & 99.91 \\
\hline PurE (\%) & 95.6 & 99.92 & 99.33 & 99.66 & 99.43 \\
\hline$Y\left(\mathrm{~g}_{\text {prod }} / \mathrm{g}_{\mathrm{CSP}} / \mathrm{d}\right)$ & 0.60 & 0.91 & 0.62 & 0.98 & 0.62 \\
\hline $\operatorname{RecR}(\%)$ & 85 & 100 & 99.86 & 100 & 99.90 \\
\hline $\operatorname{Rec} E(\%)$ & 99.9 & 99.08 & 97.98 & 98.98 & 99.43 \\
\hline$S C\left(\mathrm{~m}_{\text {desorbent }}^{3} / \mathrm{kg}_{\text {prod }}\right)$ & 0.922 & 0.613 & 0.586 & 0.576 & 0.565 \\
\hline
\end{tabular}

${ }^{\mathrm{a}}$ Ludemann-Hombourger et al., 2002. 
Table Vd. Single objective optimization results as described in cases $1 \mathrm{~d}$ and $2 \mathrm{~d}$.

\begin{tabular}{|c|c|c|c|c|c|}
\hline \multirow{2}{*}{$\begin{array}{l}\text { Performance } \\
\text { parameter }\end{array}$} & \multicolumn{3}{|c|}{ Six-column Varicol } & \multicolumn{2}{|c|}{ Six-column SMB } \\
\hline & L-H et al., $2002^{\mathrm{a}}$ & Case 1 & Case 2 & Case 1 & Case 2 \\
\hline$Q_{1}(\mathrm{~mL} / \mathrm{min})$ & 15.3 & 15.3 & 15.3 & 15.3 & 15.3 \\
\hline$Q_{F}(\mathrm{~mL} / \mathrm{min})$ & 0.33 & $0.53(+59 \%)$ & 0.33 & $0.50(+50 \%)$ & 0.33 \\
\hline$Q_{D}(\mathrm{~mL} / \mathrm{min})$ & 9.05 & 9.05 & $5.60(-38 \%)$ & 9.05 & $5.72(-37 \%)$ \\
\hline$Q_{R}(\mathrm{~mL} / \mathrm{min})$ & 1.89 & 4.46 & 1.29 & 2.36 & 1.20 \\
\hline$t_{s}(\min )$ & 1.11 & 0.84 & 0.85 & 1.04 & 0.88 \\
\hline$\chi(-)$ & $1 / 2.25 / 2 / 0.75$ & $\mathrm{~S} / \mathrm{S} / \mathrm{Q} / \mathrm{T}$ & $\mathrm{R} / \mathrm{S} / \mathrm{O} / \mathrm{S}$ & $\mathrm{O}$ & $\mathrm{O}$ \\
\hline$Q_{E}(\mathrm{~mL} / \mathrm{min})$ & 7.49 & 5.11 & 4.64 & 7.19 & 4.85 \\
\hline PurR (\%) & 99.7 & 99.95 & 100 & 100 & 99.99 \\
\hline PurE (\%) & 95.6 & 99.66 & 99.60 & 99.49 & 99.60 \\
\hline$Y\left(\mathrm{~g}_{\text {prod }} / \mathrm{g}_{\mathrm{CSP}} / \mathrm{d}\right)$ & 0.664 & 1.104 & 0.696 & 1.031 & 0.683 \\
\hline $\operatorname{RecR}(\%)$ & 85.1 & 100 & 100 & 100 & 100 \\
\hline $\operatorname{RecE}(\%)$ & 99.9 & 99.33 & 99.20 & 96.60 & 99.02 \\
\hline$S C\left(\mathrm{~m}_{\text {desorbent }}^{3} / \mathrm{kg}_{\text {prod }}\right)$ & 0.888 & 0.533 & 0.532 & 0.571 & 0.544 \\
\hline
\end{tabular}

${ }^{\text {a}}$ Ludemann-Hombourger et al., 2002.

the objective function, constraints, decision variables, and fixed parameter values used in this study. Five decision variables $\left(Q_{D}, Q_{R}, t_{s}, L_{c o l}, \chi\right)$ have been used in the optimization study. Since $Q_{F}$ and $Q_{1}$ (this comes directly from fixing the maximum allowable pressure drop in the system) have been fixed, only two other flow rates (among $Q_{D}, Q_{R}, Q_{E}, Q_{2}, Q_{3}$, and $Q_{4}$ ) could be determined independently. We selected $Q_{D}$ and $Q_{R}$ as the two decision variables. Switching time $\left(t_{s}\right)$, length of each column $\left(L_{c o l}\right)$ and distribution (for SMB) and sequence (for Varicol) of columns were selected as the other decision variables.

The relative performance of four-column Varicol, fivecolumn SMB, and Varicol is assessed under the same conditions and the result is shown in Figure 7. The Pareto optimal solution obtained represents the maximum possible productivity and purity of raffinate streams. The benefit of multiobjective optimization study is evident upon observing the wide range of operating points available in the optimal Pareto set. If conventional techniques were used, we would have been able to predict only one point at a time on the Pareto optimal curves, by fixing either one and maximizing the other. The figure clearly shows that the five-column Varicol offers more room for improvement as indicated by the magnitude of the Pareto set, followed by five-column SMB and four-column Varicol. The maximum attainable productivity and purity of raffinate stream in a four-column Varicol system are less than that which could be obtained in a five-column SMB. In other words, the increase achieved in a five-column SMB system is due to the increase of one column, which outweighs the improvement attainable due to the increase in flexibility in a four-column foursubinterval Varicol system, which however, does not imply any additional cost. Each point on the Pareto set corresponds to a set of decision variables. The optimum configuration for four-column four-subinterval Varicol in the Pareto set is

Table VI. Multi-objective optimization problems solved in this study.

\begin{tabular}{|c|c|c|c|c|c|}
\hline \multicolumn{2}{|c|}{ Problem } & \multirow{2}{*}{$\begin{array}{l}\text { Objective function } \\
\text { Max PurR } \\
\text { Max PrR }\end{array}$} & \multirow{2}{*}{$\begin{array}{l}\text { Constraints } \\
\text { PurR }>90 \% \\
\text { PurE }>99 \%\end{array}$} & \multirow{2}{*}{\begin{tabular}{l}
\multicolumn{1}{c}{ Decision variables } \\
$8<Q_{D}<15 \mathrm{~mL} / \mathrm{min}$ \\
$2<Q_{R}<10 \mathrm{~mL} / \mathrm{min}$ \\
$0.3<t_{s}<1 \mathrm{~min}$ \\
$3<L_{c o l}<7 \mathrm{~cm}$ \\
$\chi[$ See Table IV]
\end{tabular}} & \multirow{2}{*}{$\begin{array}{l}\text { Fixed variables } \\
\\
Q_{1}=17.5 \mathrm{~mL} / \mathrm{min} \\
Q_{F}=0.3 \mathrm{~mL} / \mathrm{min} \\
N_{c o l}=4 \text { or } 5\end{array}$} \\
\hline Case 3 & $\begin{array}{c}\text { SMB } \\
\text { Varicol }\end{array}$ & & & & \\
\hline Case 4 & $\begin{array}{c}\text { SMB } \\
\text { Varicol }\end{array}$ & $\begin{array}{l}\text { Max PurE } \\
\text { Max PrE }\end{array}$ & $\begin{array}{l}\text { PurR }>99 \% \\
\text { PurE }>90 \%\end{array}$ & $\begin{array}{l}8<Q_{D}<15 \mathrm{~mL} / \mathrm{min} \\
2<Q_{R}<10 \mathrm{~mL} / \mathrm{min} \\
0.3<t_{s}<1 \mathrm{~min} \\
3<L_{c o l}<7 \mathrm{~cm} \\
\chi \text { [See Table IV] }\end{array}$ & $\begin{array}{l}Q_{1}=17.5 \mathrm{~mL} / \mathrm{min} \\
Q_{F}=0.3 \mathrm{~mL} / \mathrm{min} \\
N_{c o l}=4 \text { or } 5\end{array}$ \\
\hline Case 5 & $\begin{array}{l}\text { SMB } \\
\text { Varicol }\end{array}$ & $\begin{array}{l}\operatorname{Max} Q^{F} \\
\operatorname{Min} Q^{D}\end{array}$ & $\begin{array}{l}\text { PurR }>99 \% \\
\text { PurE }>99 \%\end{array}$ & $\begin{array}{l}0.2<Q_{F}<0.45 \\
5<Q_{D}<10 \mathrm{~mL} / \mathrm{min} \\
1<Q_{R}<5 \mathrm{~mL} / \mathrm{min} \\
0.3<t_{s}<1 \mathrm{~min} \\
\chi \text { [See Table IV] }\end{array}$ & $\begin{array}{l}Q_{1}=17.5 \mathrm{~mL} / \mathrm{min} \\
L_{c o l}=8.1 \mathrm{~cm} \\
N_{c o l}=4 \text { or } 5\end{array}$ \\
\hline
\end{tabular}



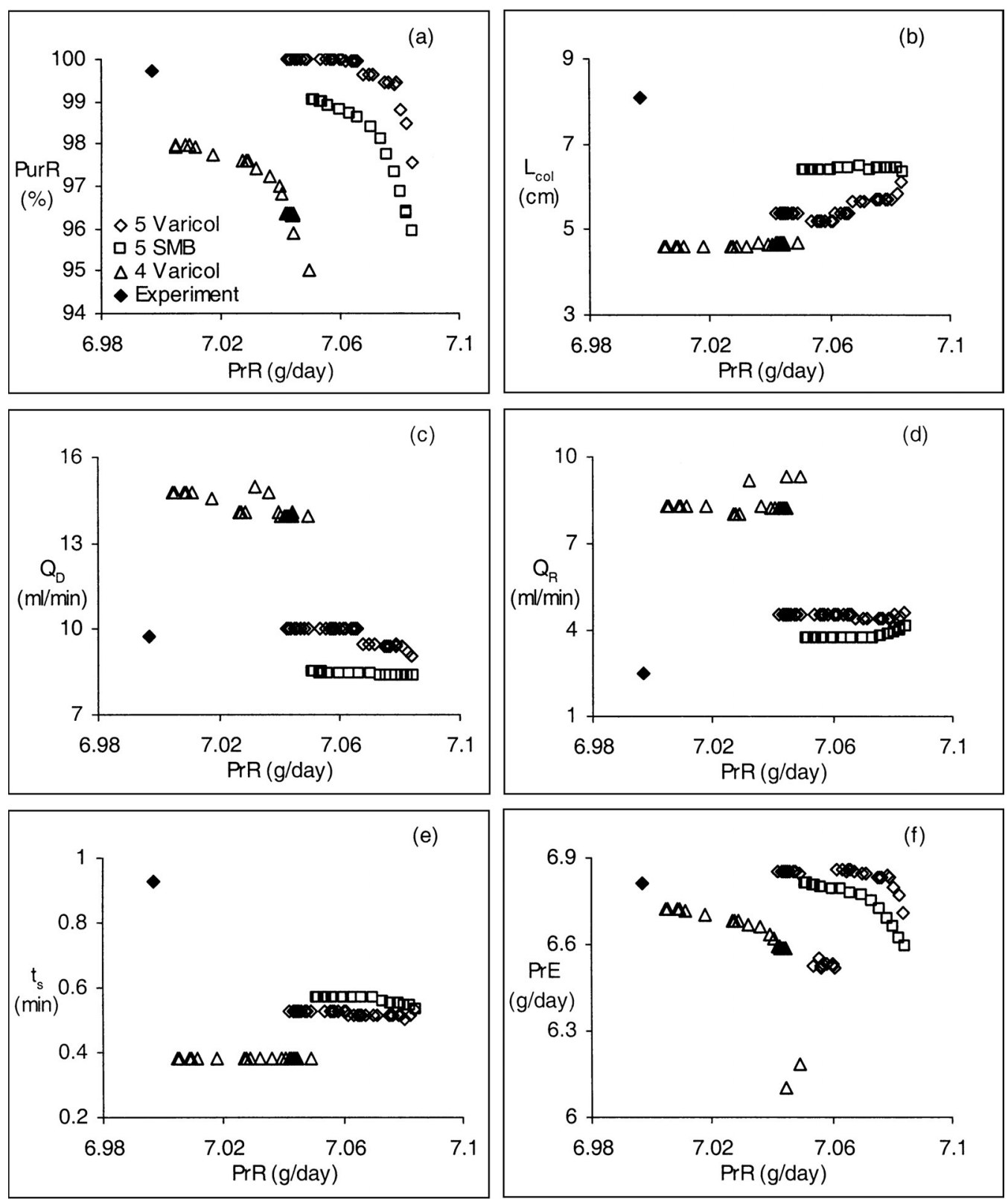

Figure 7. Pareto optimal solution and corresponding decision variables (Case 3) for SMB and Varicol systems.

$\chi=\mathrm{B}-\mathrm{A}-\mathrm{D}-\mathrm{D}$, which means the column configuration, is $0 / 2 / 1 / 1$ for the first subinterval, $0 / 1 / 2 / 1$ for the second subinterval followed by $1 / 1 / 2 / 0$ for the last two subintervals. This corresponds to an average column configuration of $0.5 / 1.25 / 1.75 / 0.5$. The optimum column configuration for a five-column SMB is $\chi=J$, which is essentially $1 / 2 / 1 / 1$, while for the five-column Varicol it is $\chi=\mathrm{I}-\mathrm{I}-\mathrm{J}-\mathrm{J}$, which corresponds to $1 / 1.5 / 1.5 / 1$. Significant transition from fourcolumn Varicol to five-column SMB and finally to fivecolumn Varicol is observed indicating the difficulty in obtaining high extract product purity (> 99\%). The optimum column distribution for both four- and five-column Varicol process indicates that zone II (between the extract withdrawal port and the feed entry port) and zone III (between the feed and raffinate withdrawal port) is critical in maximizing the productivity and purity of the raffinate product. This is expected as the primary job for zone II and zone III is to desorb less strongly adsorbed component and retain more strongly adsorb component.

\section{Case 4. Multiobjective Optimization: Maximization of Purity and Productivity of Extract Product}

The optimization problem studied in this case is similar to case 3 except it is done for maximization of productivity and purity of extract stream subject to purity of raffinate stream greater than $99 \%$ cases 3 and 4 co-exist in this study as adequate information about the relative importance of raffinate and extract product is not available and this dilemma can be resolved by assuming the two products are 
of equal importance. The Pareto set in Figure 8 shows that five-column Varicol maintains its narrow dominance over five-column SMB and four-column Varicol, and concurrently confirms the previous finding that it is relatively easier to satisfy high raffinate purity constraint than high extract purity. This is because the less-adsorbed component is always moving with the mobile phase. The optimum column configuration for four- and five-column Varicol are $\chi=\mathrm{C}-\mathrm{C}-\mathrm{E}-\mathrm{G}(\equiv 1.25 / 1.25 / 1 / 0.5)$ and $\chi=\mathrm{H}-\mathrm{J}-\mathrm{J}-\mathrm{K}(\equiv 1.25 /$ $1.5 / 1 / 1.25)$, respectively, while the same for five-column SMB is $\chi=K(\equiv 2 / 1 / 1 / 1)$. The optimal column configuration for four- and five-column Varicol requires more columns in zone I (between the desorbent and extract port) and II (between the feed and extract port) withdrawal port) as the extract is the desired product. Figure 8 also shows the corresponding plots for the decision variables. As expected, desorbent flow rate increases as extract productivity increases while raffinate flow rate is slightly scattered as this variable was found to be less sensitive towards the objective functions. One should note that the Pareto in Figure 8 and others are quite smooth unlike the plots of the decision variables. This can be easily understood if one pays attention to the large number of decision variables used in the study. This leads to a "degrees of freedom" problem. One can achieve maximum value of one objective by combination of different decision variables, such as large length and short switching time or smaller length and relatively large switching time. Sometimes a decision variable is insensitive near optimal solution and therefore, a Pareto obtained will not change whether one uses a particular value or
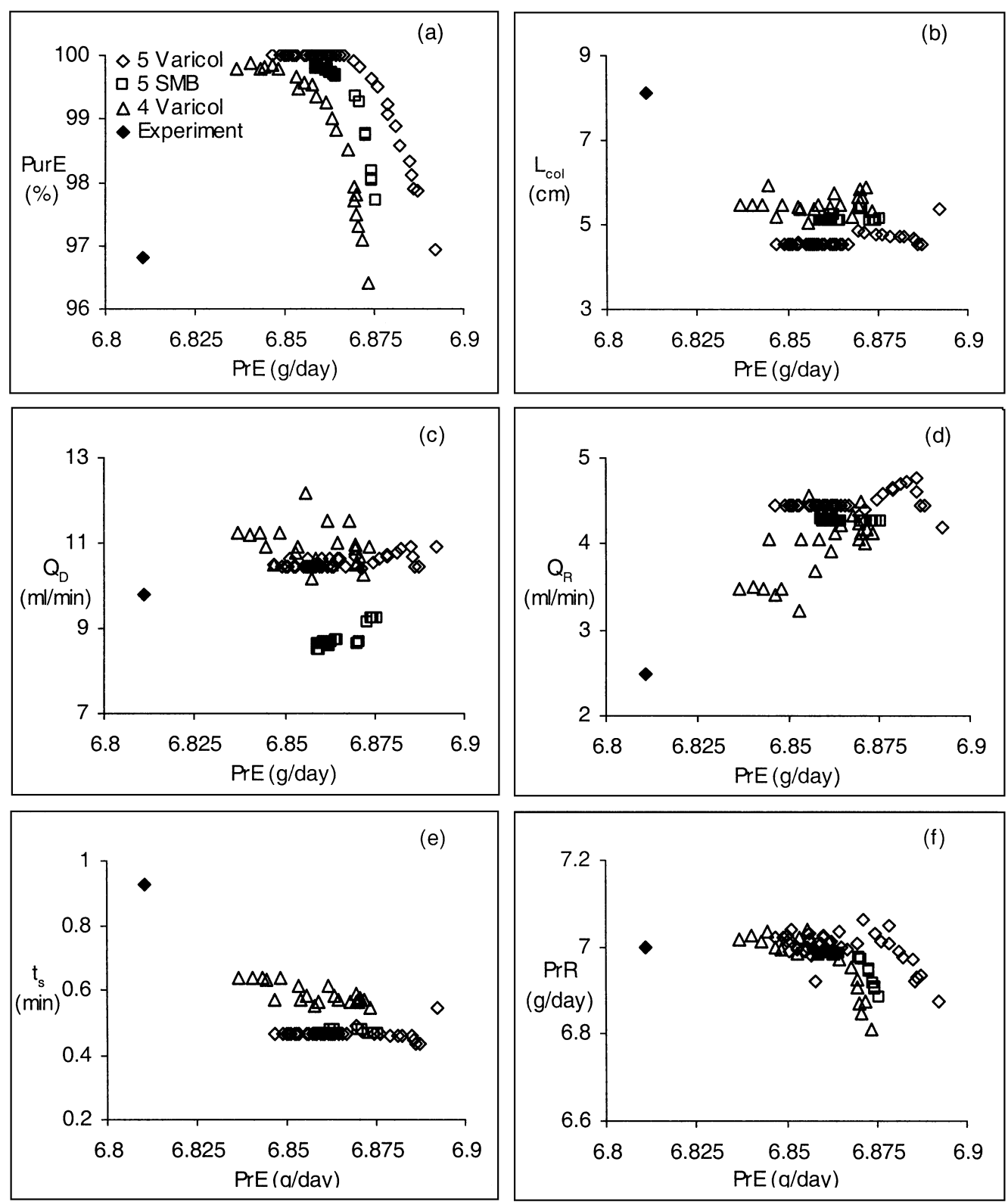

Figure 8. Pareto optimal solution and corresponding decision variables (Case 4) for SMB and Varicol systems. 
some other values around it. However, it is wise to keep as many variables as decision variables that can be controlled (manipulated) in reality to maintain operation flexibility. Hence, the scatter pattern in the decision variable plots is merely due to more degrees of freedom or insensitivity of a particular variable towards the desired objectives.

\section{Case 5. Multiobjective Optimization: Maximization of Feed Flow Rate and Minimization of Desorbent Flow Rate}

Another case of multiobjective optimization is formulated in view of economic consideration. In this case optimal process operation conditions were determined to reduce operating costs by minimizing desorbent flow rate while increasing revenue by increasing productivity through maximization of feed flow rate for product purities greater than a specified value. The optimization problem is represented mathematically as follows:

$$
\begin{gathered}
\operatorname{Max} \quad I_{1}=Q_{F}\left[Q_{F}, Q_{D}, Q_{R}, t_{s}, \chi\right] \\
\operatorname{Min} \quad I_{2}=Q_{D}\left[Q_{F}, Q_{D}, Q_{R}, t_{s}, \chi\right] \\
\text { Subject to PurE }>99 \% \\
\text { PurR }>99 \% \\
Q_{1}=175 \mathrm{~mL} / \mathrm{min}, L_{c o l}=8.1 \mathrm{~cm}, N_{c o l}=4 \text { or } 5
\end{gathered}
$$

The choice of the two objective functions enables maximum production using minimum solvent for product purities greater than $99 \%$ of both extract and raffinate streams for five-column SMB and four- and five-column Varicol systems.

Similar to earlier cases, $Q_{1}$, the column flow rate in zone I, was fixed at $17.49 \mathrm{~mL} / \mathrm{min}$ to keep the maximum system pressure drop constant, and the total CSP used was also fixed by fixing $L_{c o l}=8.1 \mathrm{~cm}$ and $N_{c o l}=4$ or 5 . The dependence of pressure drop on liquid flow rate is shown in Table I and the fact that zone I has the highest flow rate of all zones has necessitated the need to set $Q_{1}$ to keep the system working within the maximum tolerable pressure drop. The details of the optimization formulation together with the bounds used for the decision variables are reported in Table VI. Note that the two variables $\left(Q_{F}\right.$ and $\left.Q_{D}\right)$ appear in the objective functions as well as in decision variables. The Pareto optimal solutions $\left(Q_{F}\right.$ vs. $\left.Q_{D}\right)$ and the values of the associated decision variables are shown in Figure 9. The Paretos shown in the figure indicate that both the SMB and the Varicol processes need to increase the desorbent consumption to increase the feed flow rate. Second, under the same conditions, the Varicol process consumes less desorbent $\left(Q_{D}\right)$ than an equivalent SMB process for the same feed flow rate, $Q_{F}$; or for the same desorbent consumption, the Varicol process can treat more feed. Thus, it is confirmed and quantified that the flexibility due to the nonsynchronous shift of the input/output ports in a Varicol process allows achieving the same desired target purity with less eluent and/or allows treating more feed. Increasing desorbent consumption compensates the increase in amount of feed to be treated as the separation task becomes more difficult. More desorbent is needed to ensure sufficient desorption of the strongly adsorbed component from the adsorbent. The optimum column configuration for fourcolumn Varicol is C-B-C-D ( $\equiv 0.75 / 1.25 / 1.25 / 0.75)$ while for five-column SMB is $\mathrm{H}(\equiv 1 / 1 / 1 / 2)$ and for five-column Varicol is I-H-K-J ( $\equiv 1.25 / 1.25 / 1.25 / 1.25)$. The trends are expected as more desorbent is needed when the feed flow rate is increased. Again, five-column Varicol outweigh four-column Varicol and five-column SMB and it conveys that five-column Varicol consume less desorbent or for the same amount of desorbent, it can treat more feed compared to four-column Varicol and five-column SMB.

To better understand the reliability of the optimization results it is worthwhile to discuss the results using equilibrium theory applied to countercurrent chromatography (Storti et al., 1995). They showed that the unit behavior could be explained in terms of the flow rate ratio parameters relative to the four zones of the unit:

$$
m_{j}=\frac{Q_{j} t_{s}-V_{c o l} \varepsilon}{V_{c o l}(1-\varepsilon)}, \quad j=1 \approx 4
$$

In particular, the flow rate ratio parameter $m_{1}$ has to be larger than a critical value ( $\sigma_{i}$ in Eq. (13) to be less than 1 for both components) to achieve complete regeneration of the solid phase from the strongly adsorbed (heavy) component, while $\mathrm{m}_{4}$ has to be smaller than a critical value $\left(\sigma_{i}>1\right.$ for both components) to achieve complete regeneration of the liquid phase from the weakly adsorbed (light) component. Once both such conditions are satisfied, it is possible to identify in the $\left(\mathrm{m}_{2}-\mathrm{m}_{3}\right)$ parameter plane a triangular region, which includes all pairs of values leading to complete separation $(\sigma>1$ for one component and $\sigma<1$ for the other), i.e., the two components are recovered pure in the extract and in the raffinate, respectively. This region, which depends only on the adsorption isotherms and the feed concentrations, has been calculated and is represented in Figure 10 for five-column SMB and in Figure 11 for fivecolumn Varicol process. In the upper right region, with respect to that of complete separation, a pure extract stream is obtained, while the raffinate is polluted. In the lower left region, only the raffinate and not the extract is obtained pure. Finally, it is worth pointing out that the distance from the diagonal of a point in the $\left(\mathrm{m}_{2}-\mathrm{m}_{3}\right)$ plane is directly proportional to productivity and inversely proportional to desorbent requirement. The vertex of the complete separation triangular region thus gives the optimal operating point with respect to such two process performances.

To interpret the results of the optimization we have replotted the optimal values of the decision variables in Figure 9 in terms of the four flow rate ratio parameters, $\mathrm{m}_{j}$ as 

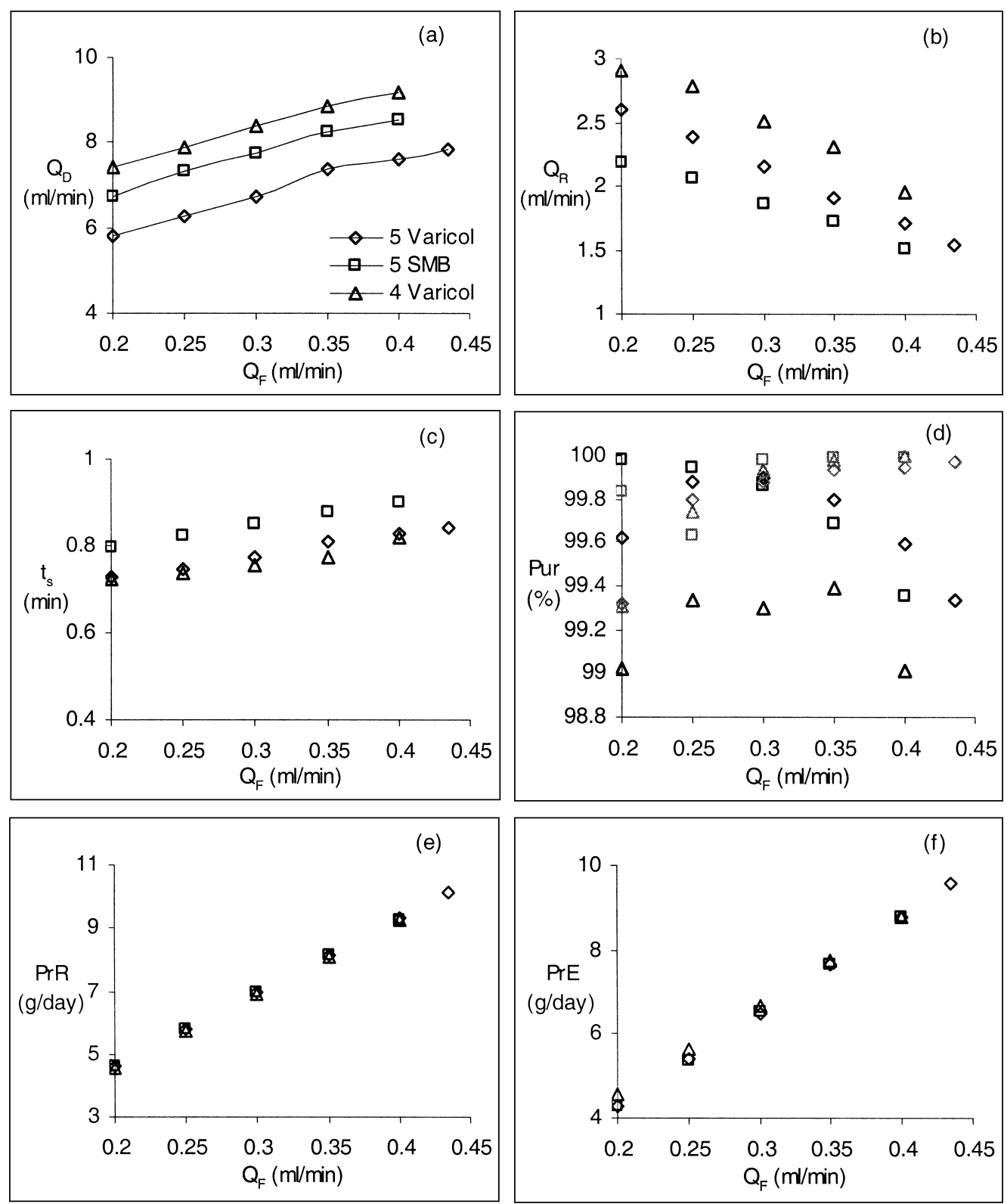

Figure 9. Pareto optimal solution and corresponding decision variables (Case 5) for SMB and Varicol systems.

shown in Figure 12 for the five-column SMB (Fig. 12a) and the five-column Varicol (Fig. 12b) process, respectively. Figure 12 reveals that all operating points on the Pareto correspond to a substantially constant value of $\mathrm{m}_{1}$, in agreement with equilibrium theory, which predict a constant lower bound for such parameter. Only for the points corresponding to the higher feed flow rate do we observe an increase of $m_{1}$. This is due to the need to improve the solid regeneration in zone I to avoid the heavier component entering zone IV and polluting the raffinate. This indicates that the zone I is critical to controlling the purity in the raffinate as production increases. We need to better control the regeneration of the solid from the heavy component in zone $\mathrm{I}$. On the other hand, $\mathrm{m}_{4}$ undergoes smaller changes, indicating that zone IV is much less critical to achieve the desired separation performance in the particular case under examination. It is seen that the values of $\mathrm{m}_{2}$ and $\mathrm{m}_{3}$ obtained in each case do change very little as the feed flow rate increases. This is consistent with the equilibrium theory result, which indicates that the optimal operating point (the vertex of the triangle) is independent of the feed and eluent flow rates. Moreover, the values of $\mathrm{m}_{2}$ and $\mathrm{m}_{3}$ should not vary a lot, according to equilibrium theory, which would see them constant and corresponding to the vertex of the complete separation region. However, due to dispersion phenomena, the same change in $\mathrm{m}_{2}$ and $\mathrm{m}_{3}$ is observed, and actually they both tend to decrease, as moving along the Pareto. Switching time increases as feed flow rate increases (see Fig. 9) because one has to increase the residence time to achieve high purity separation. The increase in switching 


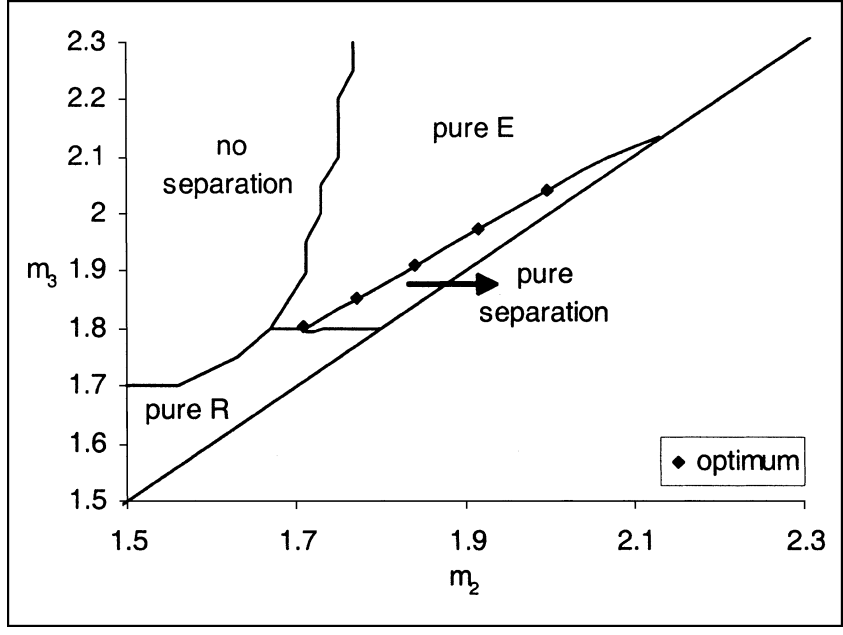

Figure 10. Optimum operating regime in $m_{2}-m_{3}$ plane for enantioseparation of SB-553261 racemate using a five-column SMB (case 5).

time initiates the increase of $\mathrm{m}_{1}$ at fixed value of $Q_{1}$. The declining value of $m_{2}$ and $m_{3}$ is expected, as the internal flow rates tend to decrease with the increase of feed flow rate. This phenomenon is consistent with the increase in switching time (Fig. 9) as contact between fluid phase and solid phase has to be maximized as the separation becomes more and more difficult. The reduction of flow rate in zone IV is merely the net effect of increasing desorbent consumption as the feed flow rate increases. The reduced flow rate compensates the increase in switching time [Eq. (19)] and it contributes to the decrease of $\mathrm{m}_{4}$. The value of $\mathrm{m}_{1}$ for five-column Varicol is somewhat smaller than that of SMB due to the smaller switching time while the magnitude of $m_{2}, m_{3}$, and $m_{4}$ for both systems are more or less similar. The comparison of $\mathrm{m}$ values in Figure 12 between SMB and Varicol systems also explain the ability of the latter to handle more feed than SMB process at the same size of triangle. As a consequence of the fact that the

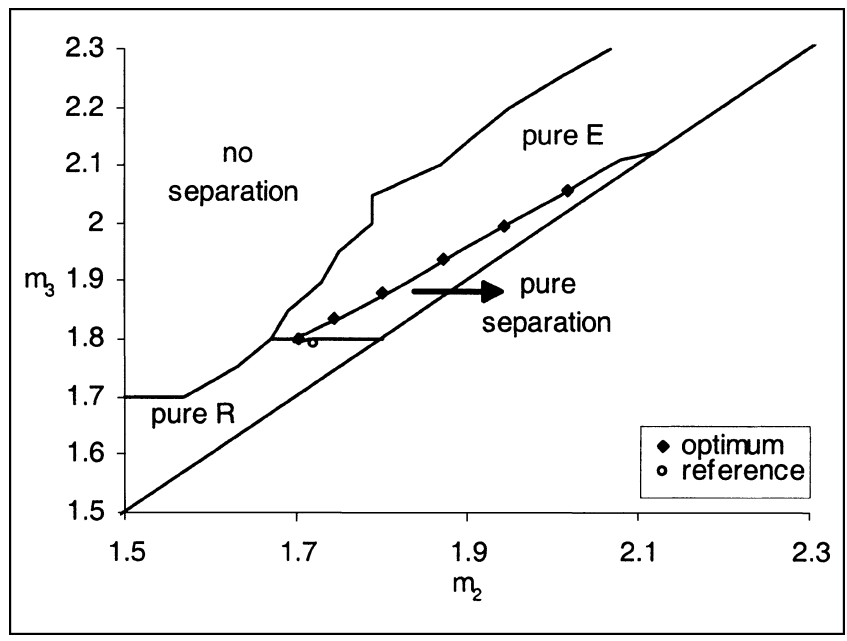

Figure 11. Optimum operating regime in $\mathrm{m}_{2}-\mathrm{m}_{3}$ plane for enantioseparation of SB-553261 racemate using five-column Varicol (case 5).

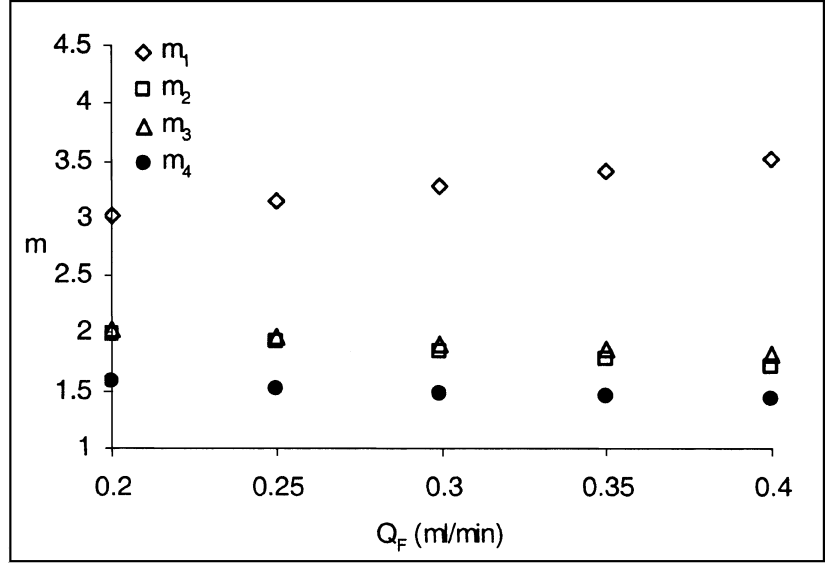

(a)

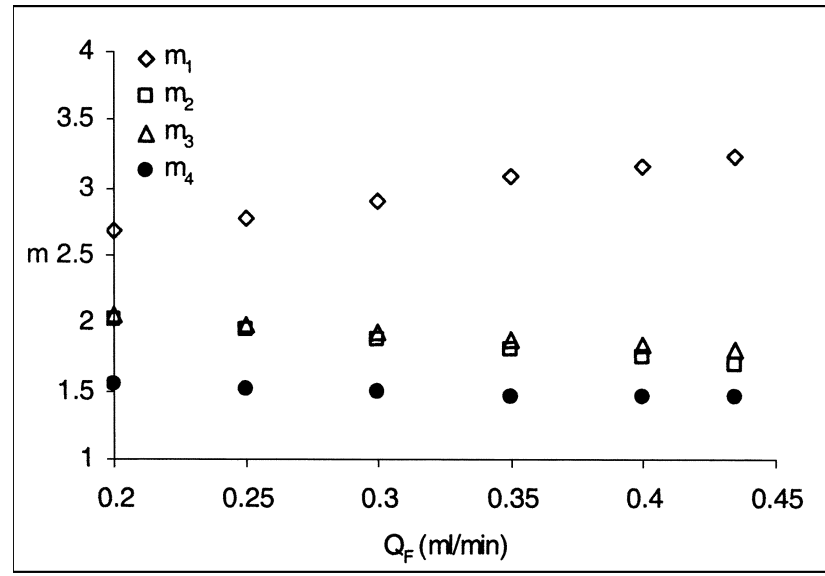

(b)

Figure 12. (a) Calculated flow rate parameter $m$ as a function of feed flow rate on a five-column SMB (case 5). (b) Calculated flow rate parameter $\mathrm{m}$ as a function of feed flow rate on a five-column Varicol (case 5).

performance of the separation (i.e., the flow rate ratio parameter values) remains substantially constant for all the operating points along the Pareto, the optimal column configuration also remains the same both for the fivecolumn SMB and the four- and five-column Varicol processes, and equal to $1 / 1 / 1 / 2,0.75 / 1.25 / 1.25 / 0.75$ and $1.25 / 1.25 / 1.25 / 1.25$, respectively. Note that the flexibility of Varicol in distributing the column in the various zones of the unit allows making such a transition more smoothly and follows the separation needs more closely than the SMB process. This justifies the improvement in its performance.

Figures 10 and 11 show the location of each optimum point within the $m_{2}-m_{3}$ plane for five-column SMB and Varicol, respectively. The complete separation region with 99\% purity requirement, which forms a triangle with the maximum amount feed that can be handled is precisely located at the vertex of the triangle. The optimum points (stretching along one side of the triangle) move toward the vertex as the feed flow rate increases. The fact that optimum points lie on the border of the triangle is expected as the optimum point will opt to move away from the diagonal 
line. Figures 10 and 11 reveal that the size of the triangle is relatively small, indicating the difficulty level for the enantio-separation and even though the size of the triangle is almost similar, Varicol can treat up to $Q_{F}=0.435 \mathrm{~mL} / \mathrm{min}$, slightly more amount of feed than $\operatorname{SMB}\left(Q_{F}=0.4 \mathrm{~mL} / \mathrm{min}\right)$ at five-column configuration. Figures 10 and 11 explicitly show that the complete separation region is independent of the feed flow rate. The above interpretation, based on equilibrium theory basic concepts, helps to rationalize the results of the optimization procedure, which when plotted in terms of the original variables (i.e., Fig. 9) appear a bit confusing.

\section{CONCLUSIONS}

Continuous large-scale chromatographic separations using simulated moving bed (SMB) technology have been of great interest in recent years, particularly in the area of chiral separations. The countercurrent movement of the solid is realized by switching the inlet and outlet ports in unison at a fixed predetermined switching time. Recently, a new system, the Varicol process, which is based on nonsynchronous shift of inlet and outlet ports, has been reported. The study shows that the performance of Varicol process can exceed the performance of SMB systems due to the flexibility offered by the former in choosing variable column switching sequences. In this work, we present a systematic study for optimal operation of SMB and Varicol process for the separation of SB-553261 racemic mixture for which experimental results have been reported recently.

The economical operation of the SMB (and Varicol) process is governed by many factors depending on capital and operation costs, productivity, and product quality. One may be interested in higher productivity using minimum solvent (eluent) or may be interested in achieving as high purity (and productivity) as possible for the raffinate (or extract) product streams. The selection of operating parameters such as column configuration (numbers, length, as well as distribution), switching time interval (in SMB) and sequence (in Varicol), and liquid flow rates in different sections is not straightforward. In most cases, conflicting requirements and constraints govern the optimal choice of the decision variables. In addition, SMB and Varicol processes operate at elevated feed concentrations leading to nonlinear competitive adsorption behaviors. In this work, we have considered a few single- and two-objective optimization problems of interest. The optimization is carried out using a very robust, nondominated sorting genetic algorithm (NSGA) with jumping genes. It works with a population of solutions and they converge into one global optima in the case of single objective optimization, and several global optima, which constitute a Pareto set (a set of optimal solutions that are equally good) in the case of multiobjective optimization.

The optimization results showed that significant improvement could be made to the chiral drug separation process using the SMB and Varicol process. Improvement of more than $50 \%$ in throughput and $30 \%$ in reduction of desorbent consumption is achieved in single-objective optimization, which is a vast improvement. It was found that the performance of a Varicol process is superior to that of a SMB process in terms of treating more feed using less eluent or increasing productivity, while at the same time achieving better product quality. Optimum results were explained using equilibrium theory by locating them in the pure separation region certifying their global optimality in the respective search space.

\section{NOMENCLATURE}

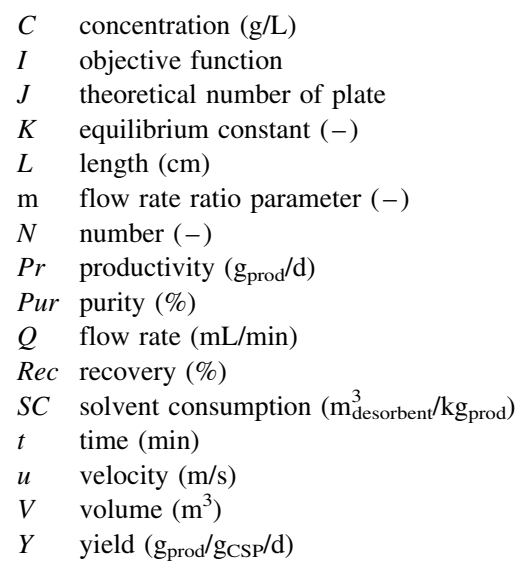

\section{Greek letters}

$\varepsilon \quad$ porosity

$\chi$ column configuration

$\sigma \quad$ relative carrying capacity

$\zeta$ pseudo solid-phase velocity

$\delta$ phase ratio

$\Delta \mathrm{P}$ pressure drop

$\phi \quad$ zone index in SMB and Varicol

Subscripts and superscripts

col column

$D$ desorbent

$E$ extract

$F$ feed

$g$ gas

$i$ component

$R$ raffinate

$s \quad$ switching, solid

\section{APPENDIX}

\section{A Note on the Optimization Technique Based on Genetic Algorithm (GA)}

Genetic Algorithm (GA) is a search technique developed by Holland (1975) that mimics the process of natural selection and natural genetics. In this algorithm, a set of decision variables are first coded in the form of a set of randomly 
generated chromosomes, thereby creating a "population" (i.e., gene pool). A model of the process is then used to provide values of the objective function (reflects its "fitness" value) for each chromosome. The Darwinian principle of "survival of the fittest" is used to generate a new and improved gene pool (new generation). This is done by preparing a "mating pool," comprising of copies of chromosomes, the number of copies of any chromosome being proportional to its fitness (Darwin's Principle). Pairs of chromosomes are then selected randomly, and pairs of daughter chromosomes generated using three operations (reproduction, crossover, and mutation) similar to those in genetic reproduction. The gene pool evolves, with the fitness improving over the generations.

To handle multiple objective functions and to find Paretooptimal solutions, the simple genetic algorithm (SGA) has been modified to Non-dominated Sorting Genetic Algorithm I (NSGA-I), which differs from SGA only in the way the selection operator works (Deb, 2001). NSGA-I uses a ranking selection method to emphasize the good points and a niche method to create diversity in the population without losing a stable subpopulation of good points. In the new procedure, several groups of nondominated chromosomes from among all the members of the population at any generation are identified. To distribute (spread out) the points evenly, the fitness value is assigned according to a sharing procedure. The population is found to converge rapidly to the Pareto set.

However, experience with NSGA-I indicates that this algorithm has some disadvantages. The sharing function used to evaluate niche count of any chromosome requires the values of two parameters, which are difficult to assign a priori. In addition, NSGA-I does not use any elitepreserving operator and so, good parents may get lost. Deb et al. (2002) have recently developed an elitist nondominated sorting genetic algorithm (NSGA-II) to overcome these limitations. In NSGA-II, a different sorting and sharing method is used, which reduces the numerical complexity to $\mathrm{MN}_{\mathrm{P}}^{2}$ operations in contrast to $\mathrm{MN}_{\mathrm{p}}^{3}$ operations required for NSGA-I, where $M$ is the number of objective functions, and $\mathrm{N}_{\mathrm{p}}$ is the number of chromosomes in the population.

Kasat et al. (2002) recently introduced a modified mutation operator, borrowing from the concept of jumping genes (JG) in natural genetics. This algorithm is being called as NSGA-II-JG. This is a macro-macro mutation, and counteracts the decrease in the diversity created by elitism. The jumping genes operation is carried out after crossover and normal mutation in NSGA-II. A part of the binary strings in the selected chromosomes is replaced with a newly (randomly) generated string of the same length. Only a single jumping gene was assumed to replace part of any selected chromosome. This helps save considerable amounts of the computation time (at times, gives correct solutions, which are missed by other algorithms) and is important for compute-intense multiobjective problems like that of the SMB and Varicol process. Nandasana et al.
(2003) has reviewed recently the applications of different adaptations of NSGA in chemical engineering.

\section{References}

Azevedo DCS, Rodrigues AE. 2001. Fructose-glucose separation in a SMB pilot unit: Modelling, Simulation, Design and Operation. AIChE J 47(9):2042-2051.

Bhaskar V, Gupta SK, Ray AK. 2000. Applications of multi-objective optimization in chemical engineering. Rev Chem Eng 16:1-54.

Broughton DB, Gerhold CG. 1961. Continuous sorption process employing fixed bed of sorbent and moving inlets and outlets. U.S. Patent 2 985589.

Bjorklund MC, Kruglov AV, Carr RW. 2001. Further studies of the oxidative coupling of methane to ethane and ethylene in a simulated countercurrent moving bed chromatographic reactor. Ind Eng Chem Res 40(10):2236-2242.

Charton F, Nicoud RM. 1995. Complete design of a simulated moving bed. J Chromatography A 702:97.

Deb K. 2001. Multi-objective optimization using evolutionary algorithms. Chicester, UK: Wiley Interscience.

Deb K, Pratap A, Agarwal S, Meyarivan TA. 2002. Fast and elitist multiobjective genetic algorithm: NSGA-II. IEEE Trans Evolutionary Computing 6:182-197.

Dünnebier G, Klatt KU. 1999. Optimal operation of simulated moving bed chromatographic processes. Computers Chem Eng 23:S195.

Dünnebier G, Fricke J, Klatt KU. 2000. Optimal design and operation of simulated moving bed chromatographic reactors. Ind Eng Chem Res 39:2290.

Guiochon G, Golshan-Shirazi SG, Katti AM. 1994. Fundamentals of preparative and nonlinear chromatography. Boston, MA: Academic Press.

Holland JH. 1975. Adaptation in natural and artificial systems. Ann Arbor, MI: University of Michigan Press.

Jensen TB, Reijns TGP, Billiet HAH, van der Wielen LAM. 2000. Novel simulated moving-bed method for reduced solvent consumption. J Chromatography A 873:149-162.

Kasat R, Kunzru D, Saraf DN, Gupta SK. 2002. Multiobjective optimization of industrial FCC units using elitist non-dominated sorting genetic algorithm. Ind Eng Chem Res 41:4765.

Kawase M, Suzuki TB, Inoue K, Yoshimoto K, Hashimoto K. 1996. Increased esterification conversion by application of the simulated moving-bed reactor. Chem Eng Sci 51:2971-2976.

Ludemann-Hombourger O, Nicoud RM, Bailly M. 2000. The "VARICOL" process: A new multicolumn continuous chromatographic process, Sep Sci Technol 35(12):1829-1862.

Ludemann-Hombourger O, Pigorini G, Nicoud RM, Ross DS, Terfloth G. 2002. Application of the "VARICOL" process to the separation of the isomers of the SB-553261 racemate. J Chromatography A 947: 59-68.

Mazzotti M, Storti G, Morbidelli M. 1997. Optimal operation of simulated moving bed units for nonlinear chromatographic separations. J Chromatography A 769:3.

Nandasana AD, Ray AK, Gupta SK. 2003. Applications of the nondominated sorting genetic algorithm (nsga) in chemical reaction engineering. Int J Chem Reactor Eng 1:R2.

Pais LS, Loureiro JM, Rodrigues AE. 1997. Modelling, simulation and operation of a simulated moving bed for continuous chromatographic separation of 1,1'-bi-2-naphtol enantiomers. J Chromatography A 769: $25-35$.

Petroulas T, Aris R, Carr RW. 1985. Analysis and performance of a countercurrent moving-bed chromatographic reactor. Chem Eng Sci 40:2233-2240.

Ray AK, Carr RW, Aris R. 1994. The simulated countercurrent movingbed chromatographic reactor-A novel reactor separator. Chem Eng Sci 49(4):469-480. 
Ray AK, Carr RW. 1995. Experimental study of a laboratory-scale simulated countercurrent moving bed chromatographic reactor. Chem Eng Sci 50(14):2195-2202.

Rekoske JE. 2001. Chiral separations. AIChE J 47(1):2.

Schulte M, Ditz R, Devant RM, Kinkel JM, Charton F. 1997. Comparison of the specific productivity of different chiral stationary phases used for simulated moving-bed chromatography. J Chromatography A 769: $93-100$.

Storti G, Baciocchi R, Mazzotti M, Morbidelli M. 1995. Design of optimal operating conditions of simulated moving bed adsorptive separation units. Ind Eng Chem Res 34:288.

Strube J, Jupke A, Epping A, Schmidt-Traub H, Schulte M, Devant R.
1999. Design, optimization and operation of SMB chromatography in the production of enatiomerically pure pharmaceuticals. Chirality 11:440.

Wu DJ, Ma Z, Wang NHL. 1999. Optimization of throughput and desorbent consumption in simulated moving bed chromatography for paclitaxel purification. J Chromatography A 855:71.

Zhang Z, Hidajat K, Ray AK, Morbidelli M. 2002a. Multiobjective optimization of simulated moving bed system and Varicol process for chiral separation. AIChE J 48(12):2800.

Zhang Z, Hidajat K, Ray AK. 2002b. Multiobjective optimization of simulated counter-current moving bed chromatographic reactor (SCMCR) for MTBE synthesis. Ind Eng Chem Res 41:3213. 